\title{
تصميمات مقترحة لحقائب الحجاج والمعتمرين في ضوء العوامل الأرجونومية الهجاجية
}

\author{
فاطمة أحمد الثمر اني \\ طالبة دكتور اه تخصص إنما تصميم أزياء \\ كلية علوم الانسان والتصاميم - جامعة الملك عبد العزيز ـ المملكة العربية السعودية \\ أ.د. نيرمين عبد الباسط محمد \\ أستاذ تصميم الأزياء \\ كلية علوم الآنسان والتصاميم - جامعة الملك عبد العزيز ـ المملكة العربية السعودية
}

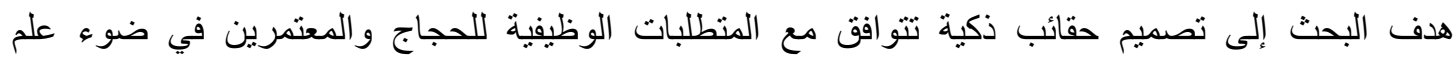

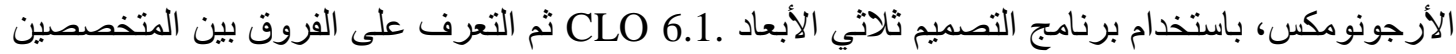

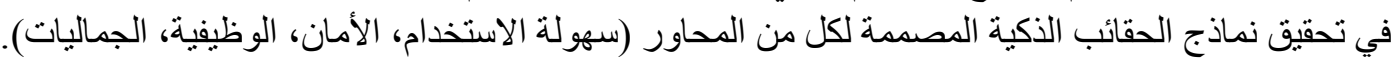

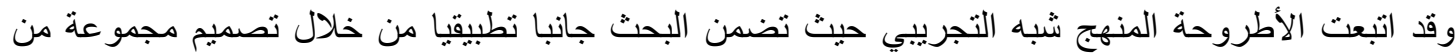

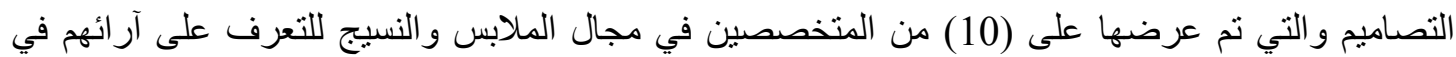
المقترحات التصميمية للحقائب الذكية و عددها (6) تصاميم وسيتم تنفيذ التصميم الأعلى تقييما. و أظهرت نتائج البحث وجود فروق دالة إحصائيا عند مستوى (0.01) بين التصميمات الست المقات المقترحة للحقائب

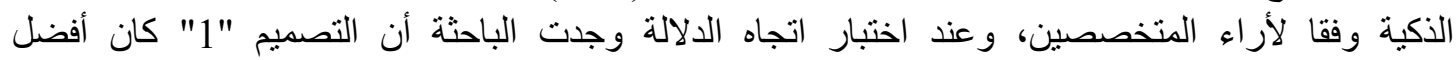

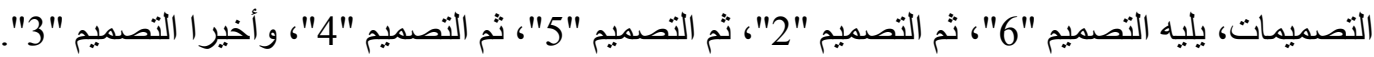

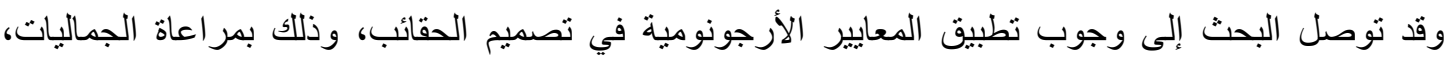

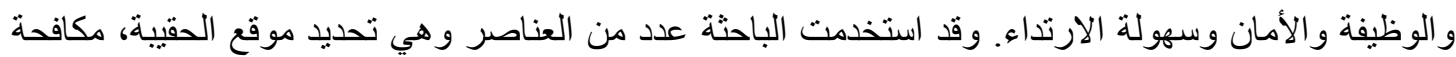
حالات السرقة، إمكانية شحن الأجهزة الذكية من خلالها. احتو ائها على تقنية RFID لتحديد هوية المستخدم.

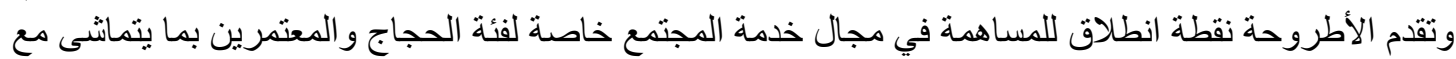

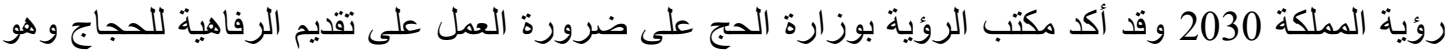

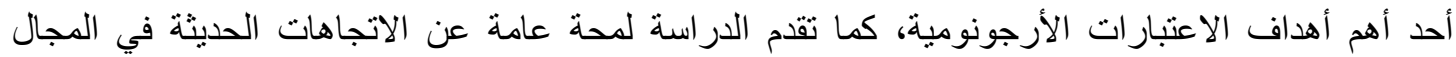

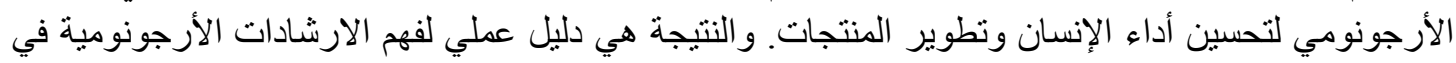

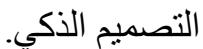

الكلمات المفتاحية: الحقائب، العو امل الأرجونومية، مكملات الملابس، حقائب الحج و العمرة. 


\title{
Bags Design for Hajj and Umrah Considering Ergonomic Factors
}

\author{
Fatimah Ahmed Saeed Al-Shamrani \\ PhD student, Fashion Design \\ College of Human Sciences and Designs - King Abdulaziz University - Saudi Arabia
}

Prof. Dr. Nermeen Abdel Rahman Abdel Basset Mohamed

Professor of Fashion Design

College of Human Sciences and Designs - King Abdulaziz University - Saudi Arabia

\begin{abstract}
The study was aims at designing smart bags that comply with the functional requirements of pilgrims using ergonomic aspects. And to identify the differences between specialists' opinion in smart bags designed for each of the (ease of use, safety, functionality, aesthetics).

The study followed the quasi-experimental approach, by designing a set of bags, which were presented to (10) specialists to know their opinions on the (6) designs.

The results of the study showed statistical differences at the level (0.01) between the six smart bags according to the opinions of specialists, the researchers found that design " 1 " was the best design, followed by design " 6 ", then design " 2 ".

The study showed that ergonomic standards should be applied in smart design. The researchers used several elements, locating the bag, combating theft cases, and the ability to charge smart devices through it. It contains RFID technology to identify the user. The study contributes to the field of community service, especially for the pilgrims.

The researcher recommended the necessity of considering the ergonomic aspects of fashion design, especially smart ones. And conducting several studies dealing with the impact of ergonomic considerations on fashion design.
\end{abstract}

Keywords: bags, ergonomic factors, Hajj and Umrah bags. 


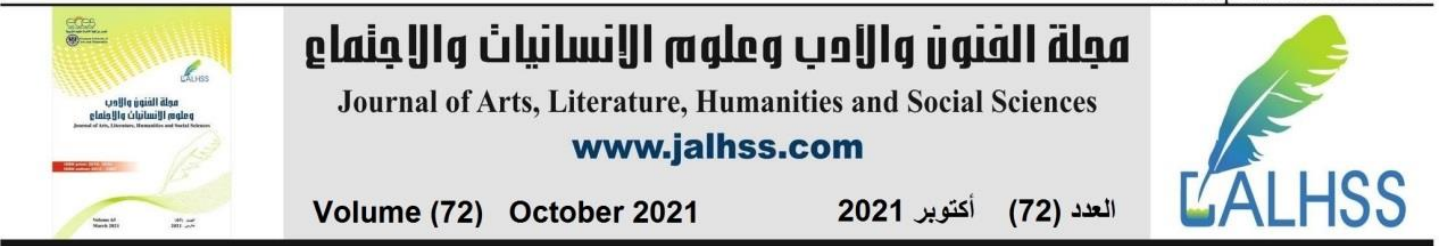

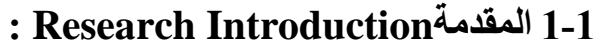

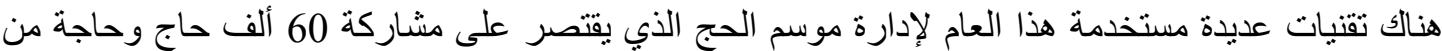

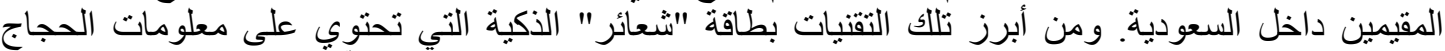

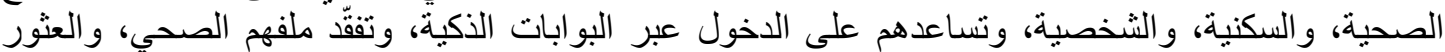

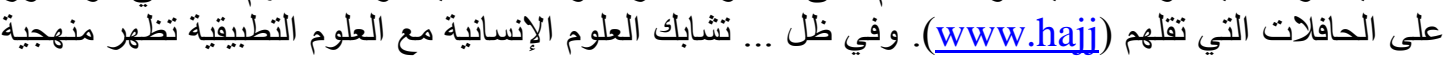

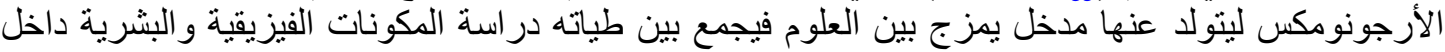

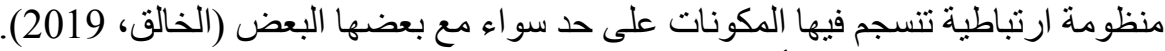

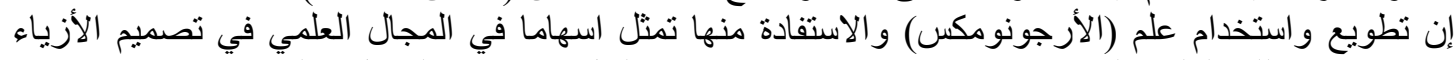

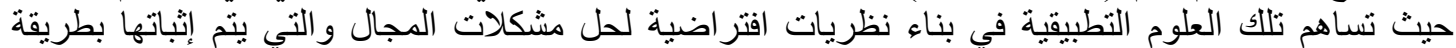

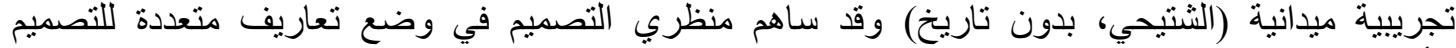

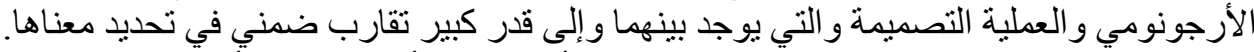

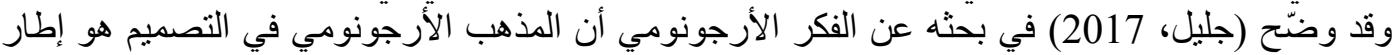

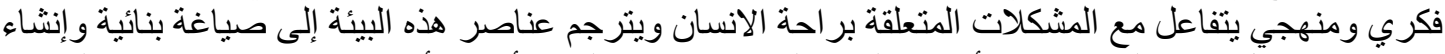

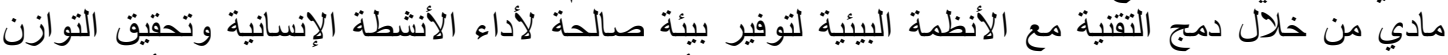

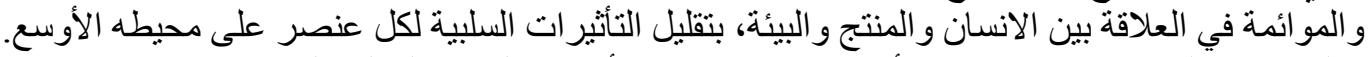

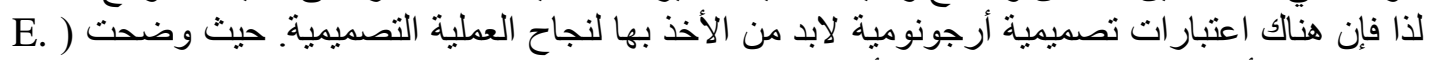

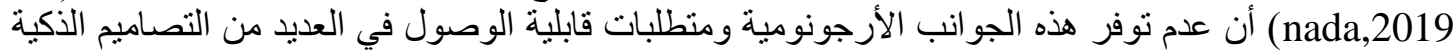

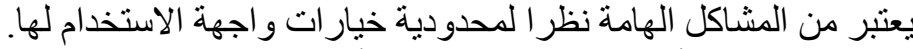

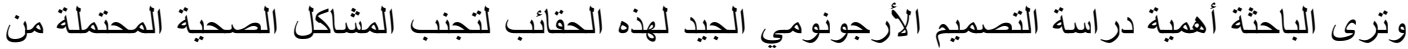

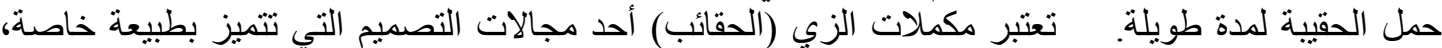

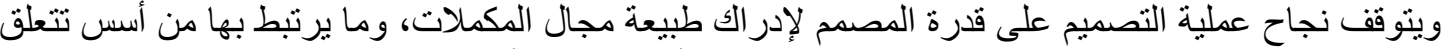

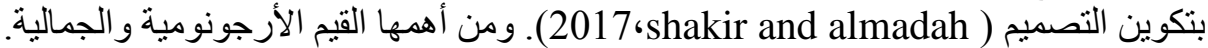

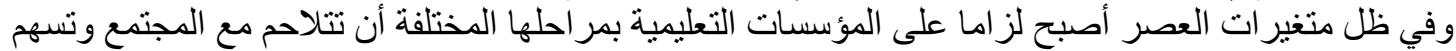

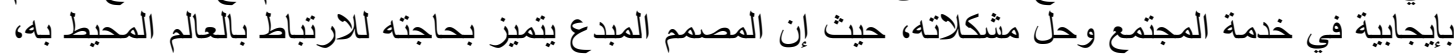

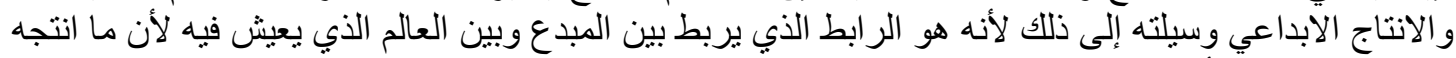

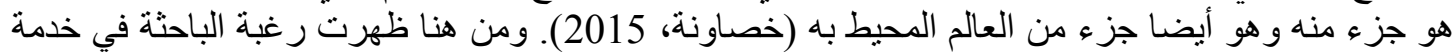

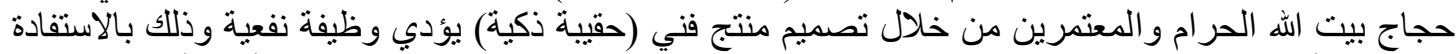

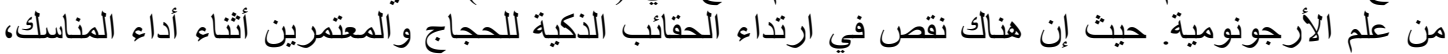

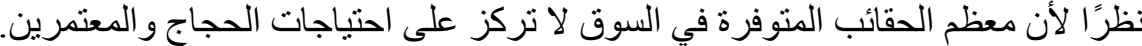

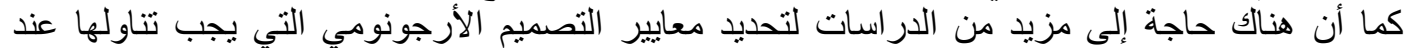

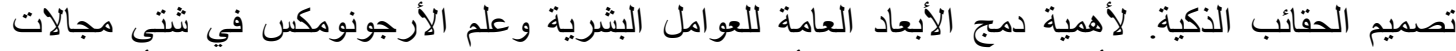

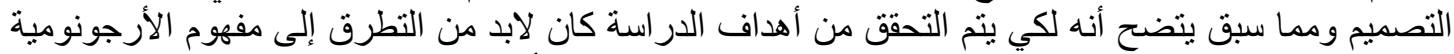

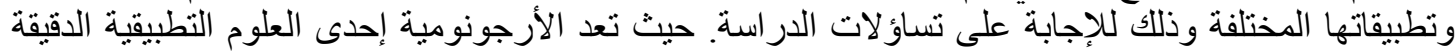

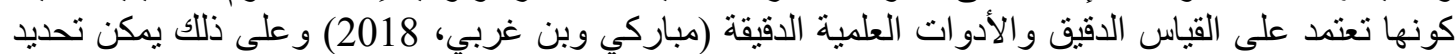

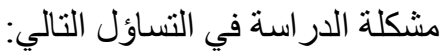
1. ما لمساهمة التي يقدمها علم الأرجونومكس في تصميم حقائب ذكية تتو افق مع المتطلبات الوظيفية ل الحجاج و المعتمرين؟ 2. هل توجد فروق دالة إحصائيا بين نماذج الحقائب الذكية المصممة لتحقيق كل من المحاور (سهولة

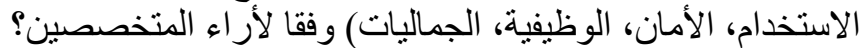

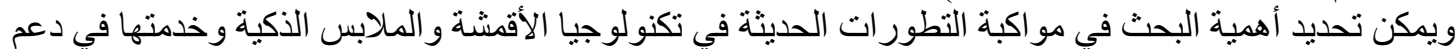

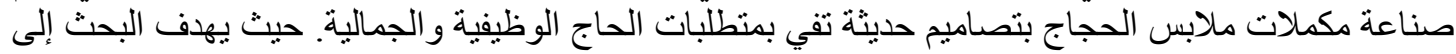

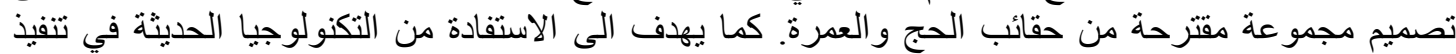
حقيبة ذكية لتلبية منطلبات الحجاج و المعتمرين. 


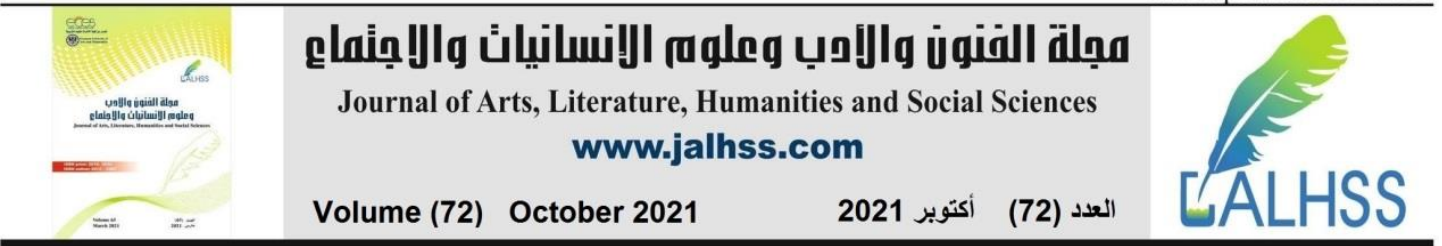

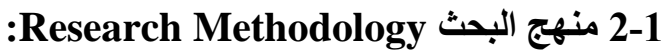

اتبعت الدراسة المنهج شبه التجريبي وذلك في الاستفادة من التكنولوجيا الحديثة في تحقيق قيم وظيفية من

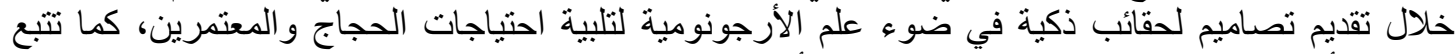

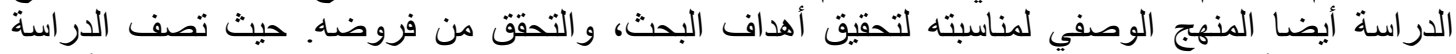

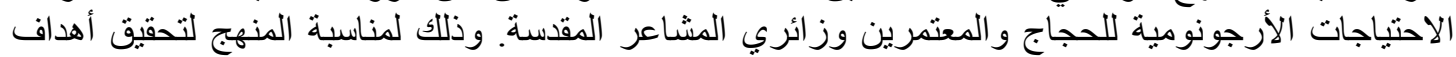

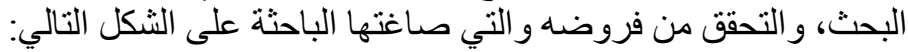

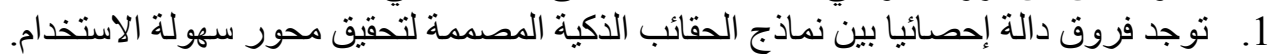

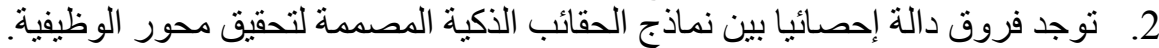

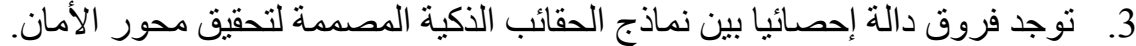

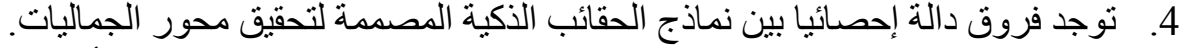
5. توجد فروق ذات دلالة إحصائية بين التصميمات المقترحة للحقائب الذكية وفقا لأر اء المتخصصين

1-2-1 إجراءات البحث Search procedures

1. تصميم مجمو عة من الحقائب الذكية باستخدام عدد من بر امج الحاسب المختلفة وهي:6.1 6.1

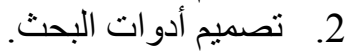

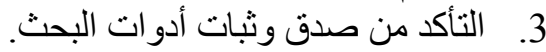

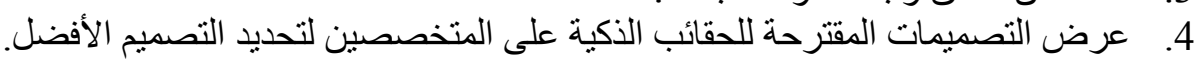
5. استخدام التحليل الاحصائي المناسب لتحليل النتائج.

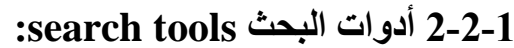

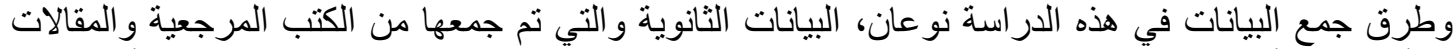

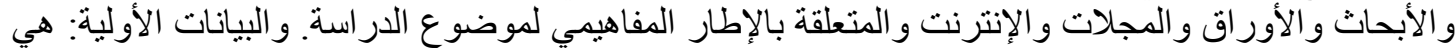

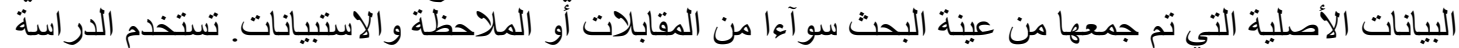

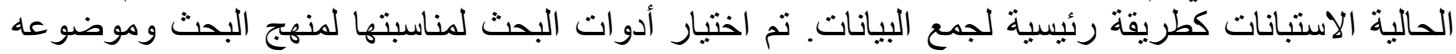

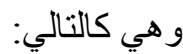

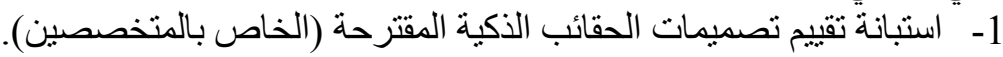

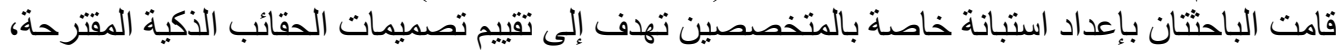

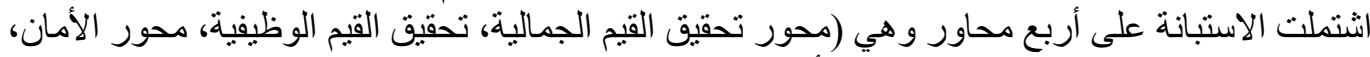

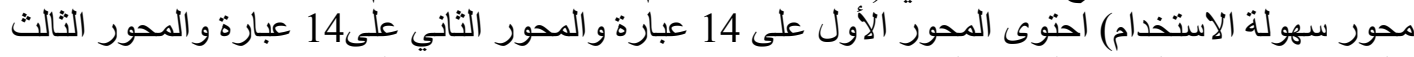

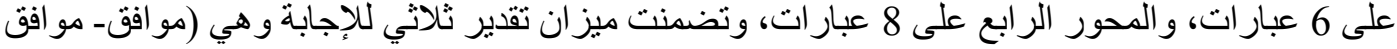

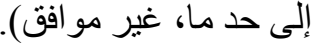

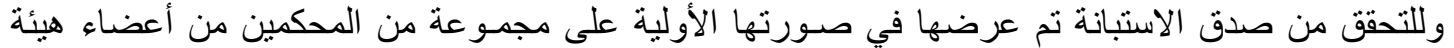

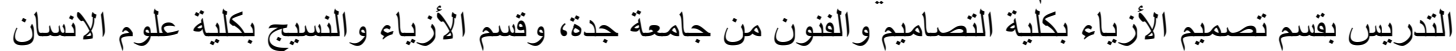

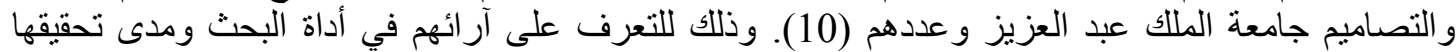

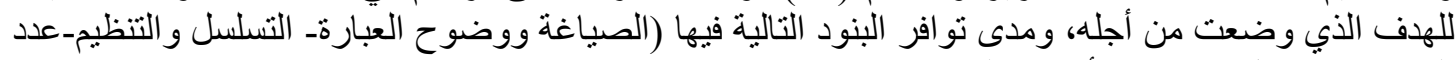

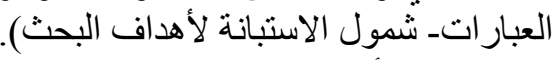

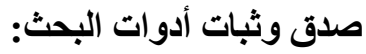

استبانة تقييم تصميمات الحقائب الذكية المقترحة "خاص بالمتخصصين": صدق الاستبانة: هو أن تؤدي وتقيس أسئلة الاستبانة ما وضعت لقياسه فعلاً. 


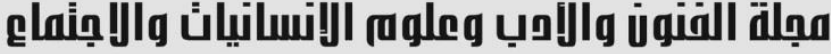

Journal of Arts, Literature, Humanities and Social Sciences www.jalhss.com

1- حساب معاملات ألارتباط بين درجة كل عبارة من العبارات المكونة لكل محور، والدرجة الكلية للمحور بالاستبيان.

2- حساب معاملات الارتباط بين الدرجة الكلية لكل محور من محاور الاستبانة و الدرجة الكلية بالاستبيان.

المحور الأول: تحقيق القيم الجمالية:

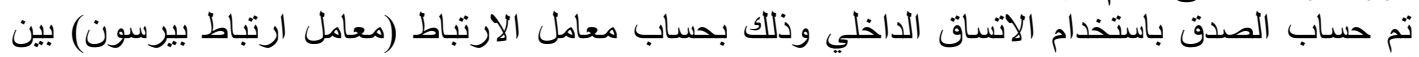

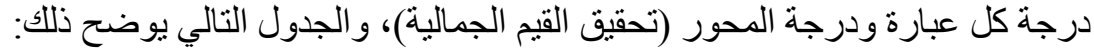

جدول (1) قيم معاملات الارتباط بين درجة كل عبارة ودرجة المحور (تحقيق القيم الجمالية)

\begin{tabular}{|c|c|c|c|c|c|}
\hline الدالآة & الارتباط & م & الدلالة & الارتباط & م \\
\hline 0.01 & 0.792 & 7 & 0.01 & 0.825 & 1 \\
\hline 0.05 & 0.607 & 8 & 0.01 & 0.761 & 2 \\
\hline 0.01 & 0.857 & 9 & 0.05 & 0.619 & 3 \\
\hline 0.01 & 0.709 & 10 & 0.01 & 0.887 & 4 \\
\hline 0.05 & 0.632 & 11 & 0.01 & 0.734 & 5 \\
\hline 0.01 & 0.943 & 12 & 0.01 & 0.915 & 6 \\
\hline
\end{tabular}

يتضح من الجدول أن معاملات الارتباط كلها دالة عند مستوى (0.01 - 0.05) لاقترابها من الواحد

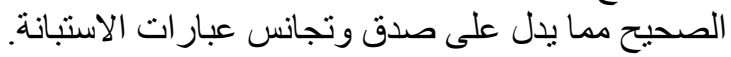

المحور الثاني: تحقيق القيم الوظيفية: تم حساب الصدق باستخدام الاتساق الداخلي وذللك بحساب معامل الارتباط (معامل ارتباط بيرسون) بين درجة كل عبارة ودرجة المحور (تحقيق القيم الوظيفية)، والجدول التالي يوضح ذللك:

جدول (2) قيم معاملات الارتباط بين درجة كل عبارة ودرجة المحور (تحقيق القيم الوظيفية)

\begin{tabular}{|c|c|c|c|c|c|}
\hline الدلالة & الارتباط & م & الدلالة & الارتباط & 5 \\
\hline 0.01 & 0.745 & 8 & 0.05 & 0.643 & 1 \\
\hline 0.01 & 0.951 & 9 & 0.01 & 0.804 & 2 \\
\hline 0.01 & 0.814 & 10 & 0.01 & 0.773 & 3 \\
\hline 0.01 & 0.752 & 11 & 0.01 & 0.869 & 4 \\
\hline 0.05 & 0.621 & 12 & 0.01 & 0.715 & 5 \\
\hline 0.05 & 0.605 & 13 & 0.01 & 0.924 & 6 \\
\hline & & & 0.01 & 0.832 & 7 \\
\hline
\end{tabular}

يتضح من الجدول أن معاملات الارتباط كلها دالة عند مستوى (0.01 - 0.05) لاقترابها من الواحد الصحيح مما يدل على صدق وتجانس عبار ات الاستبانة.

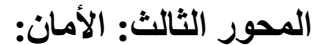
تم حساب الصدق باستخدام الاتساق الداخلي وذلك بحساب معامل الارتباط (معامل ارتباط بيرسون) بين

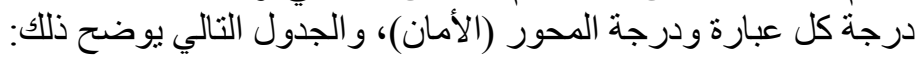




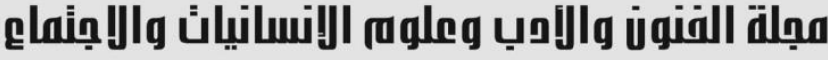

Journal of Arts, Literature, Humanities and Social Sciences www.jalhss.com

Volume (72) October 2021

أكتوبر 2021

العدد (72) (2) (2)

جدول (3) قيم معاملات الارتباط بين درجة كل عبارة ودرجة المحور (الأمان)

\begin{tabular}{|c|c|c|c|c|c|}
\hline الالالالة & الارتباط & م & الدلالة & الارتباط & م \\
\hline 0.01 & 0.796 & 5 & 0.01 & 0.878 & 1 \\
\hline 0.01 & 0.945 & 6 & 0.01 & 0.727 & 2 \\
\hline 0.01 & 0.821 & 7 & 0.05 & 0.631 & 3 \\
\hline & & & 0.01 & 0.845 & 4 \\
\hline
\end{tabular}

يتضح من الجدول أن معاملات الارتباط كلها دالة عند مستوى (0.01 - 0.05) لاقترابها من الواحد الصحيح مما يدل على صدق وتجانس معادلان عبار الات الاستبانة.

المحور الرابع: سهولة الاستخدام: تم حساب الصدق باستخدام الاتساق الداخلي وذللك بحساب معامل الارتباط (معامل ارتباط بيرسون) بين درجة كل عبارة ودرجة المحور (سهولة الاستخدام)، و الجدول التالي يوضح ذلكالك:

جدول (4) قيم معاملات الارتباط بين درجة كل عبارة ودرجة المحور (سهولة الاستخدام)

\begin{tabular}{|c|c|c|c|c|c|}
\hline الدلالة & الارتباط & م & الدلالة & الارتباط & م \\
\hline 0.01 & 0.764 & 5 & 0.01 & 0.936 & 1 \\
\hline 0.01 & 0.882 & 6 & 0.05 & 0.617 & 2 \\
\hline 0.05 & 0.644 & 7 & 0.01 & 0.788 & 3 \\
\hline 0.01 & 0.903 & 8 & 0.01 & 0.852 & 4 \\
\hline
\end{tabular}

يتضح من الجدول أن معاملات الارتباط كلها دالة عند مستوى (0.01 - 0.05) لاقتر ابها من الواحد

الصحيح مما يدل على صدق وتجانس عبار ات الاستبانة.

الصدق باستخدام الاتساق الداخلي بين الارجة الكلية لكل محور والارجة الكلية للاستبيان:

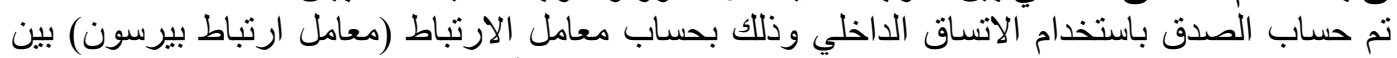

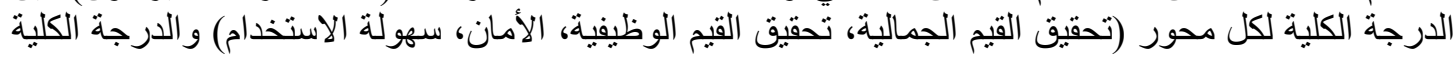

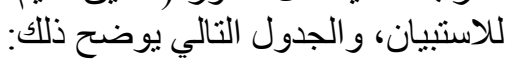

جدول (5) قيم معاملات الارتباط بين الدرجة الكلية لكل محور والدرجة الكلية للاستبانة

\begin{tabular}{|c|c|c|}
\hline الدالالة & الارتباط & المحاور \\
\hline 0.01 & 0.737 & المحور الأول: تحقيق القيم الجمالية \\
\hline 0.01 & 0.818 & المحور الثاني: تحقيق القيم الوظيفية \\
\hline 0.01 & 0.864 & المحور الثالث: الأمان \\
\hline 0.01 & 0.705 & المحور الرابع: سهولة الاستخدام \\
\hline
\end{tabular}

يتضح من الجدول أن معاملات الارتباط كلها دالة عند مستوى (0.01) لاقتر ابها من الو احد الصحيح مما يدل على صدق وتجانس محاور الاستبانة.

: Reability الثبات

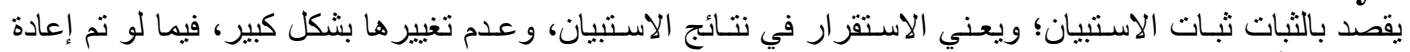
توزيعها على أفراد العينة، وقد نم التحقق من ثبات الاستبانة عن طريق معامل الفا كرو نباخ (Alpha Cronbach) و التجزئة النصفية (Split-half). 


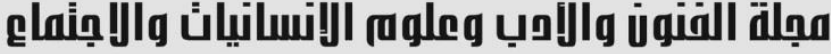

Journal of Arts, Literature, Humanities and Social Sciences www.jalhss.com

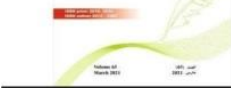

Volume (72) October 2021

كتوبر 2021

العدد (72) (2) (2)

ÁLHSS

جدول (6) قيم معامل الثبات لمحاور الاستبانة

\begin{tabular}{|c|c|c|}
\hline التجزئة النصفية & معامل & المحاور \\
\hline $0.863-0.791$ & 0.828 & المحور الأول: تحقيق القيم الجمالية \\
\hline $0.785-0.710$ & 0.741 & الدحور الثاني: تحقيق القيم الوظيفية \\
\hline $0.808-0.739$ & 0.762 & المحور الثالث: الأمان \\
\hline $0.963-0.892$ & 0.925 & المحور الر ابع: سهولة الاستخدام \\
\hline $0.907-0.835$ & 0.869 & ثبات الاستبانة ككل \\
\hline
\end{tabular}

يتضح من الجدول السابق أن جميع قيم معاملات الثبات: معامل الفا، التجزئة النصفية دالة عند مسنوى 0.01

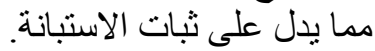

وقد طبقت الباحثنان الاستبانة على عدد من المتخصصين عددهم (10) من أعضاء هيئة التدريس بقسم تصميم

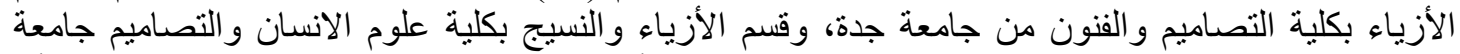

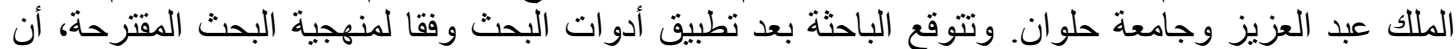

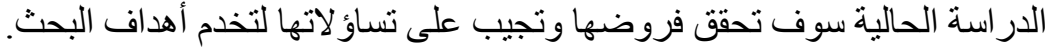

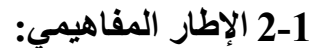

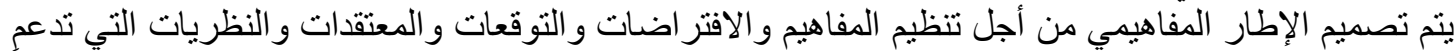

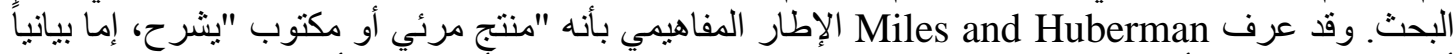

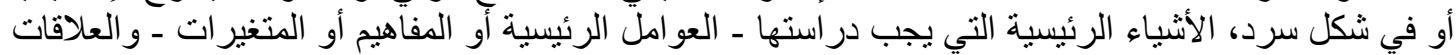

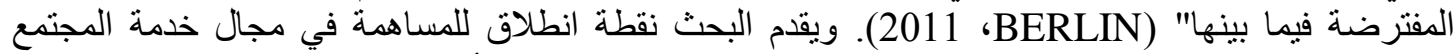

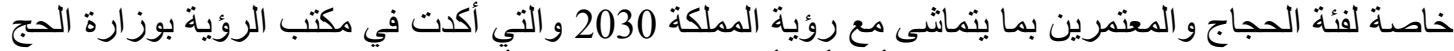
على الهمل على تقديم الرفاهية للحجاج وهو أحد أهم أهداف الاعتبار ات الأرجية التونومية.

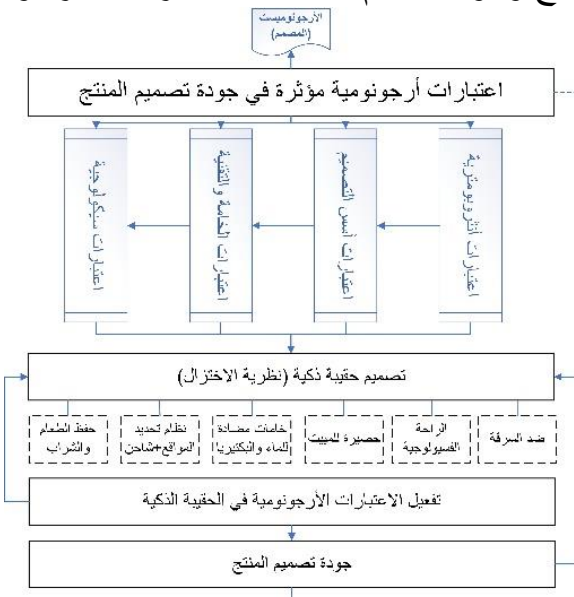

شكل (1): يوضح الإطار المفاهيمي Conceptuel Framework للبحث (تصميم الباحثة).

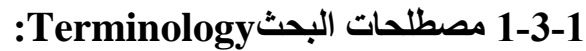
الحقائب (Bags): من مكملات الزي المنفصلة تستعمل لوضع الأغر اض و و كانت تصنع في البداية من أكياس

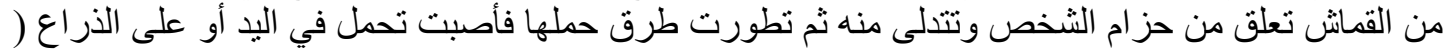

(Fawzy and others ,2020 


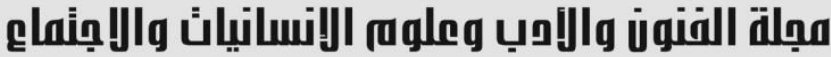 \\ Journal of Arts, Literature, Humanities and Social Sciences www.jalhss.com \\ Volume (72) October 2021 \\ 2021 كتوبر \\ العدد (72) \\ LALHSS}

العوامل الأرجونومية (Ergonomics aspects): هو نطاق علمي يتعلق بتطبيق التفاعل الناجح بين الإنسان

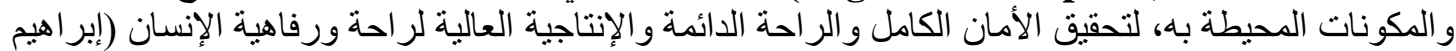
و أبو السعود، 2021)

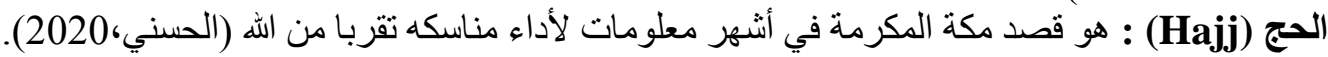

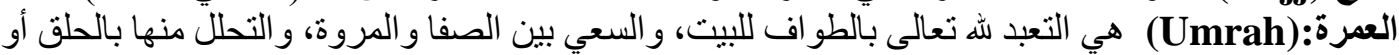
التقصبر(السرحان،2020).

حدود البحث Research Limitations: 1 1. حدود مكانية: منطقة مكة المكرمة و المشاعر المباعر المقدسة.

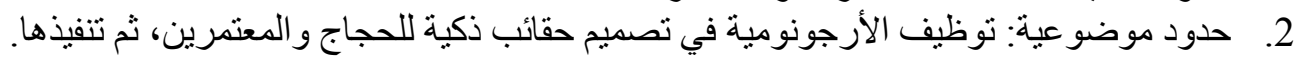

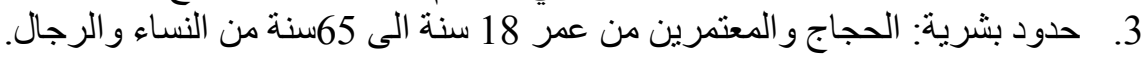

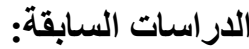

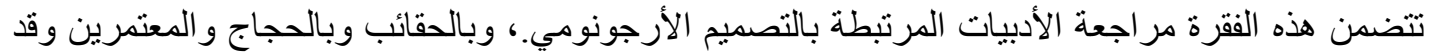

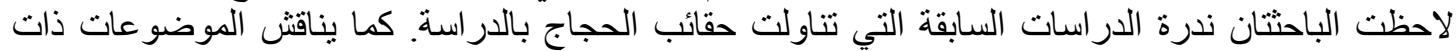

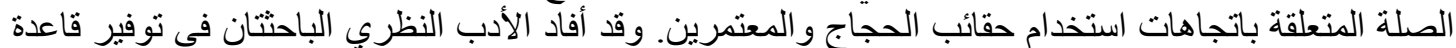
معرفية أسهمت في توجيه البحث وتطوير أداته.

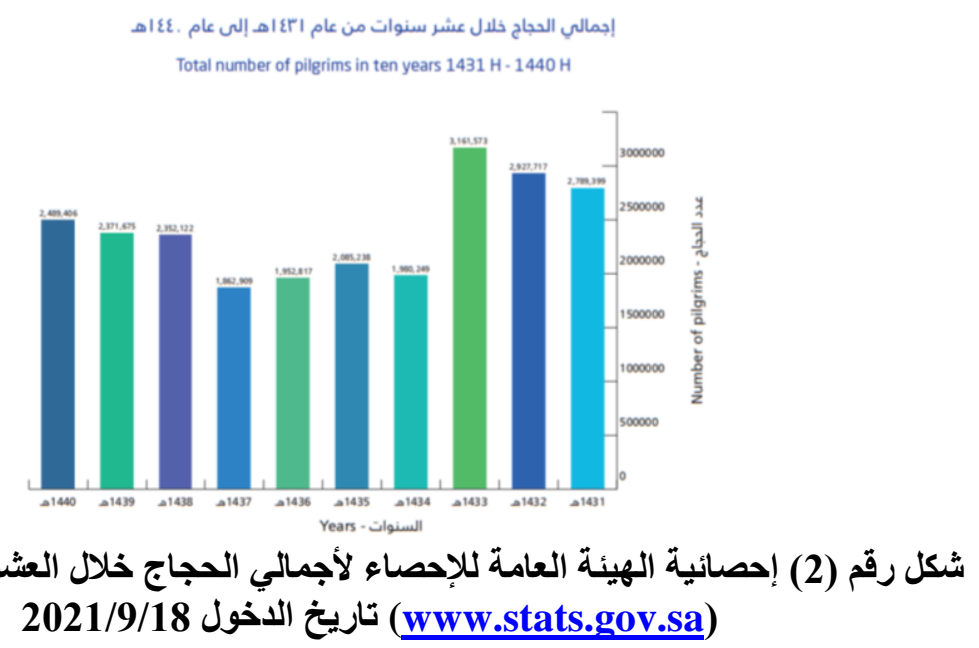

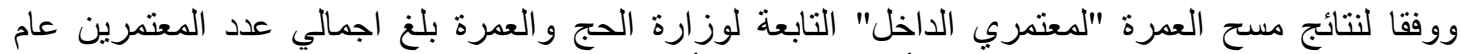

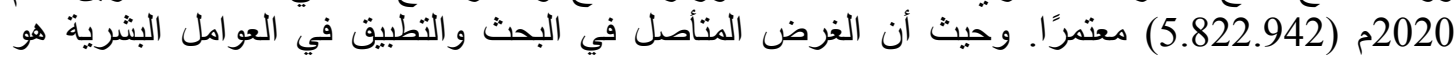

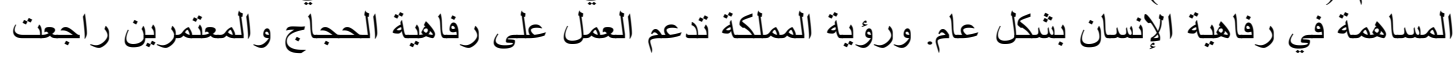

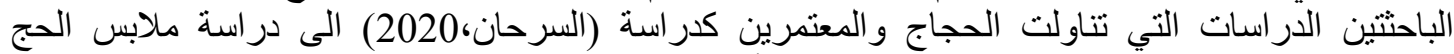

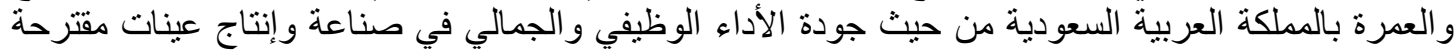

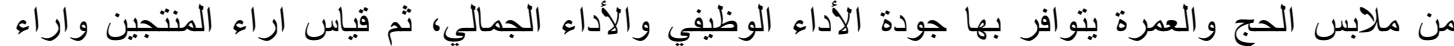
المستهلكين في عينات الملابس المقترحة.

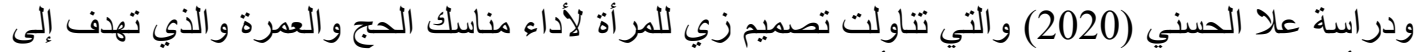

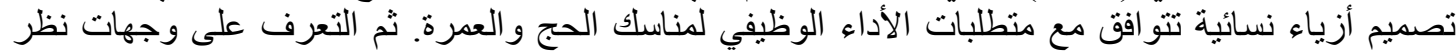
النساء "عينة البحث" نحو التصميمات المقترحة لأزياء النسائية لأداء مناسك الحج والعرة فالعمرة. وقد أوصت بأو بأهمية 


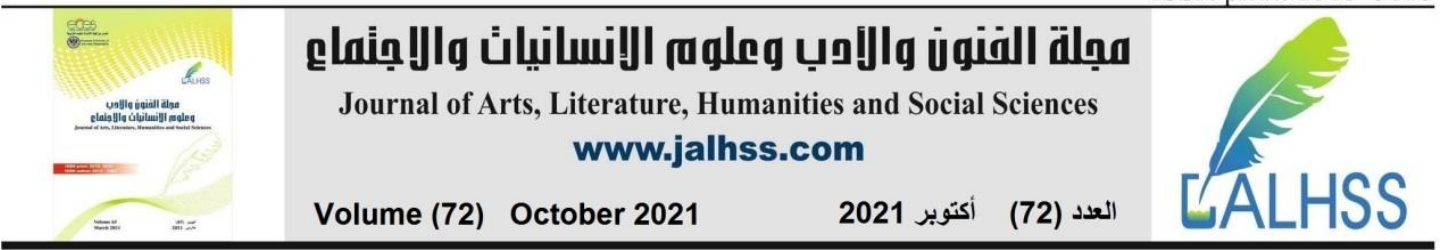

توعية الحجاج والمعتمرين بالمواصفات السليمة التي يجب أن تتوفر في ملابس الإحرام وتحقق لهم الأمان

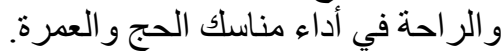
ودر اسة (بخاري وخفاجي،2015) و التي هدفت للتعرف على الخئ الخو اص الطبيعية و الميكانيكية لأقشة ملابس

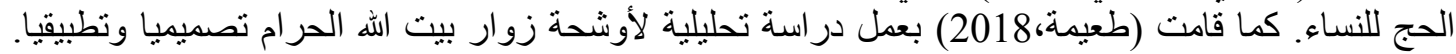

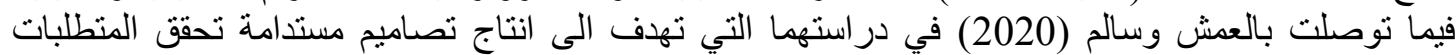
الوظيفية للباس للمر أة المحرمة إلى مدى الحاجة لمر اعاة الاحتياجات الوظيفية في المنتجات التهات أثناء أداء مناء مناسك

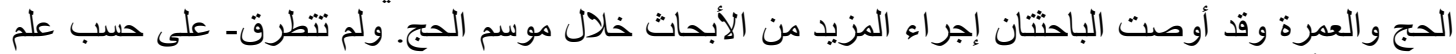

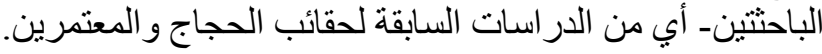

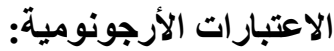

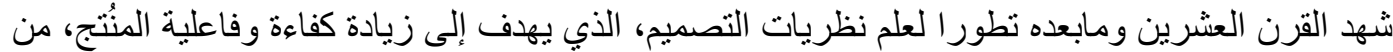

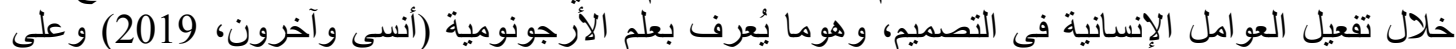

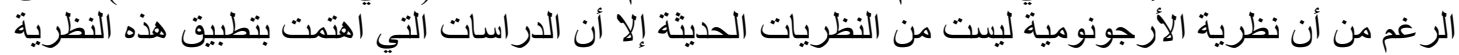

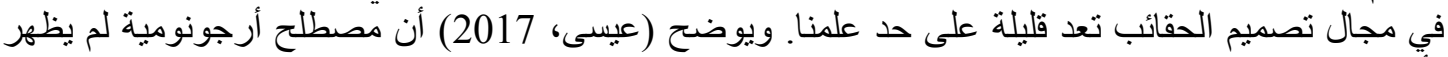

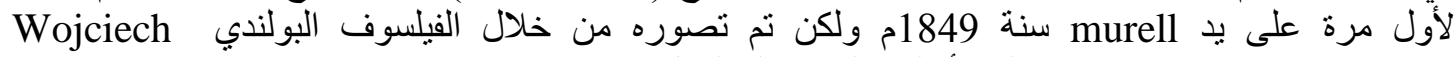
Jastrzebowski سنة الاولة 1857م و الذي أطلق عليه " علم العمل ".

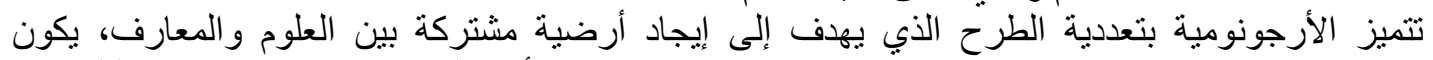

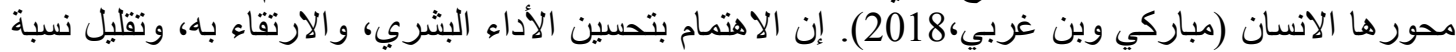

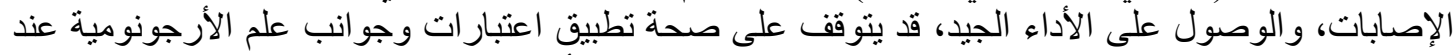
التصميم و التي تهدف إلى تطبيق النظريات، و المبادئ، و البيانات و الأساليب، في التصميم بغرض التيار تحسين معيشة

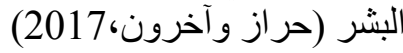

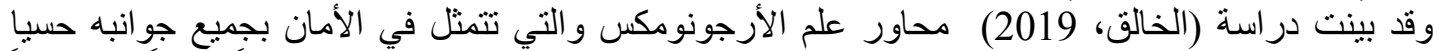

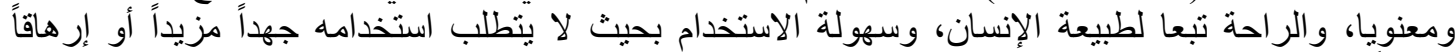

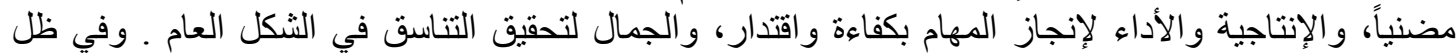

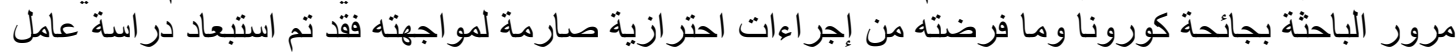

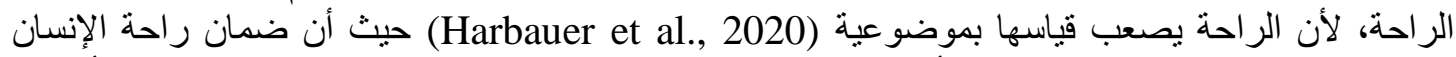

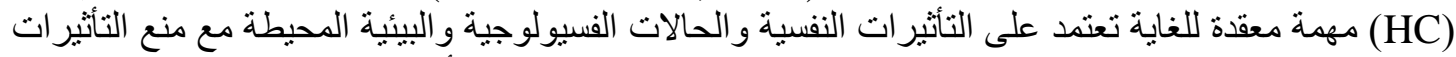

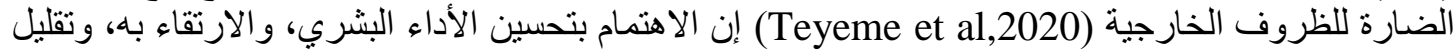

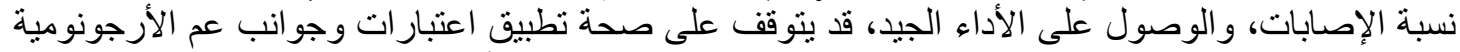

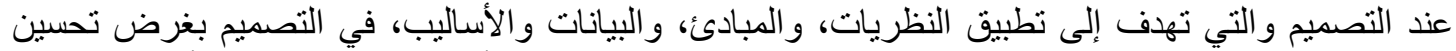

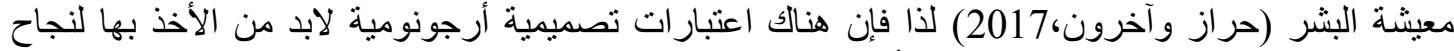
العملية التصميمية. لذا سوف تختبر الباحثة أربعة محاور فقط وهم:

\section{Aesthetic الجمالية}

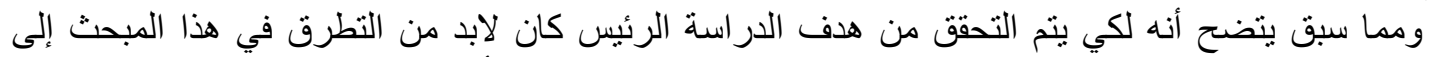

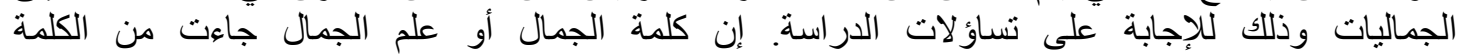

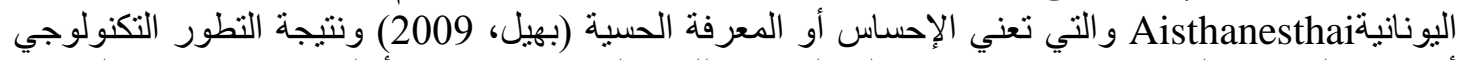

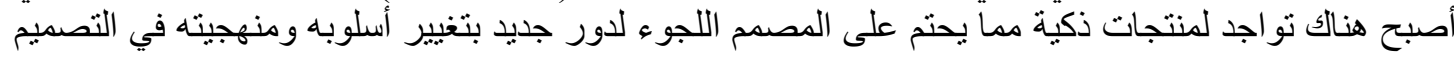

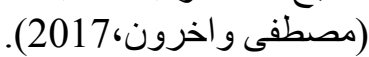

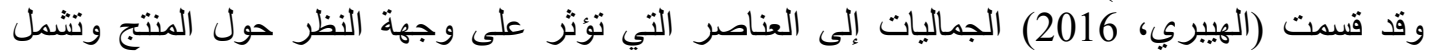

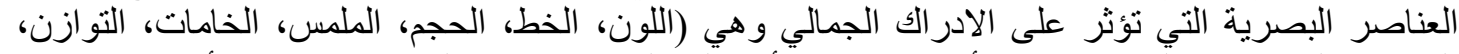

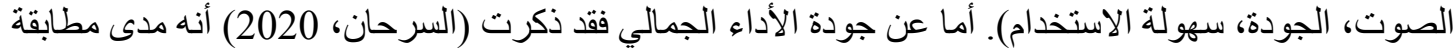
المنتج بالسمات الجمالية التي يضعها العميل كما ينبغي أن يكون جذابا ليحقي اليحق توقعات العملاء. 


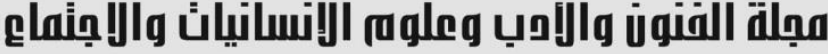

Journal of Arts, Literature, Humanities and Social Sciences www.jalhss.com

أما التقنية الجمالية فهي كما عرفها (مصطفى واخرون،2017) مجموعة من العمليات التي يمر بها التصميم من حيث العناصر و الأسس التصميمية والتكنولوجيا تبعا للفلسفة المتبعة في التصميم لتحقيق الجمال في المنتج.

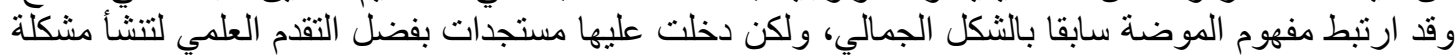
تصميم مبتكر وذكي (محمد وداوود،،2020).

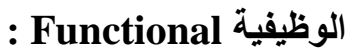
theory of functionalism حيث تتلخص هذه النظرية كما ذكرت

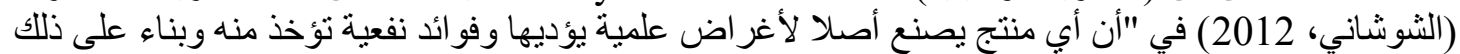

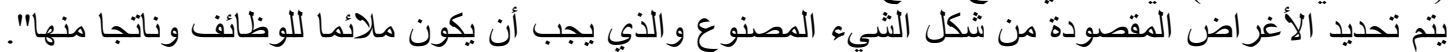
و الوظيفية كمبدأ عام تكاد أن تكون بديهية فعنصر المنفعة شرط أساسي يجب الستيفاؤه في كل مصنو عات الإنسان الإنسان

و وفي ملائمه الثكل للوظيفة (universalis.fr).

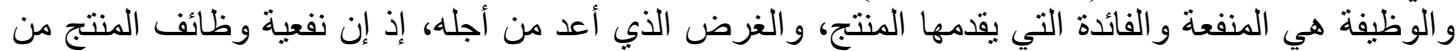

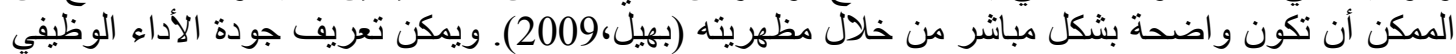

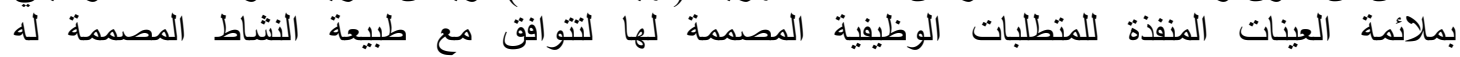
(الحج)(السرحان،2020). (الرينات والأداء الوظيفي للحقائب كما ذكرت (حربي،2020) هو ملاءمة تصميم الحقيبة للقيام بوظائفها بكفاءة وسهولة وذللك من خلال معرفة خصائص الأداء الوظيفي المطلوبة.

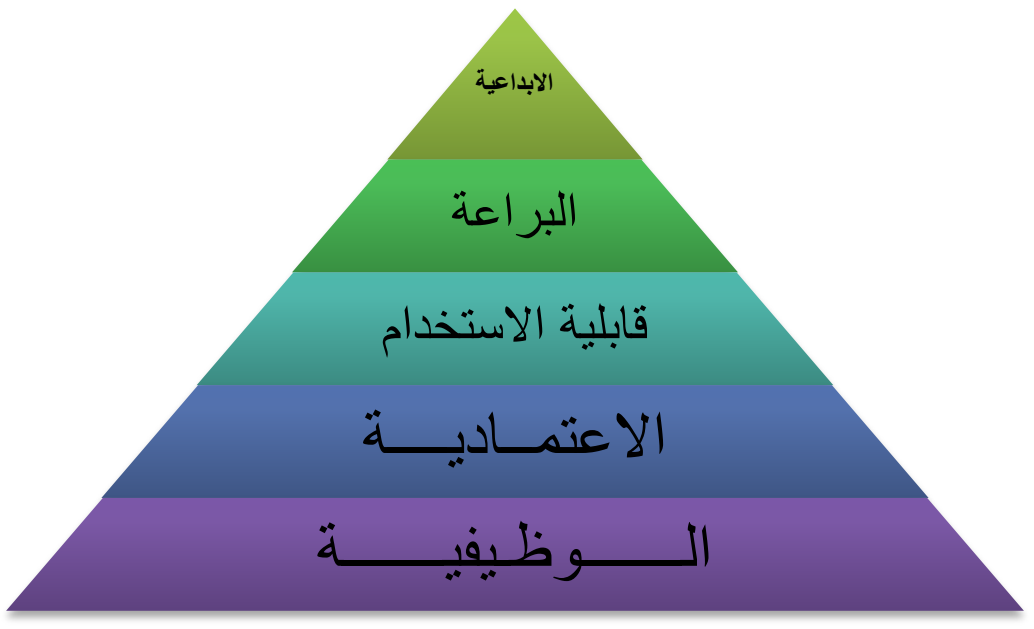

شكل رقم (3) هرم احتياجات التصميم (تصميم الباحثة)

سهولة الاستخدام Ease of use

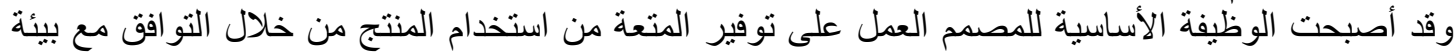

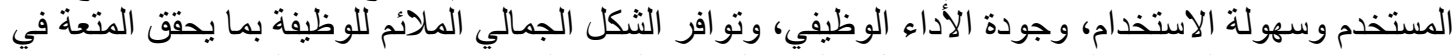

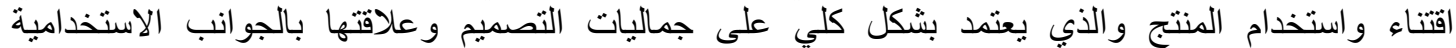

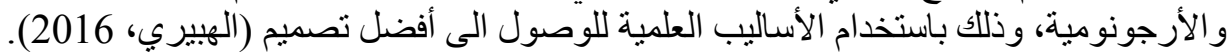

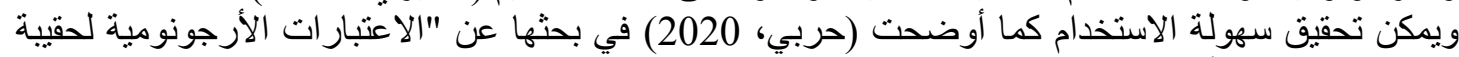

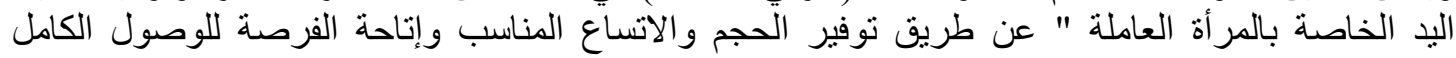

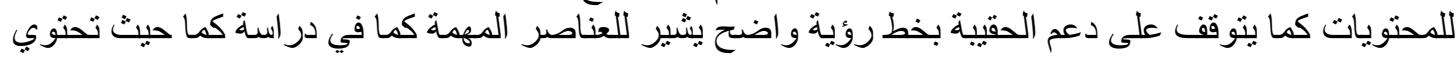
الحقيبة التي صممها على تقنية RFID لحل مشكلة النسيان عند تعبئة المحتويات المطئة المطلوبة. 


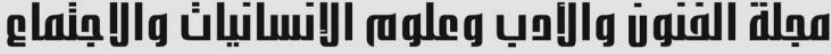

Journal of Arts, Literature, Humanities and Social Sciences www.jalhss.com

\section{Volume (72) October 2021}

2021 كتوبر

العدد (72)

LALHSS

كما تطرقت دراسة (2017،Sebin and others) لحقيبة تتبع مالكها عن طريق تقنية الكثيف عن الإنسان باستخدام مجسات الموجات فوق الصوتية. يمكن تنشيط الحقيبة عن طريق الرسائل القصيرة وأيضًا تحديد موقعها باستخدام GPS مما يسهل استخدامها.

الأمان Safety

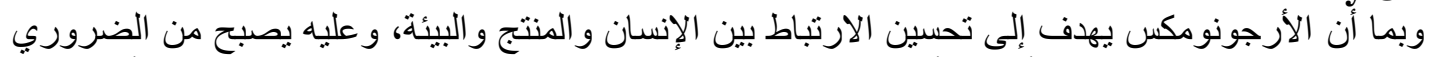

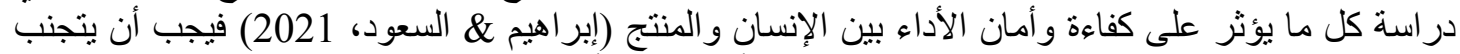

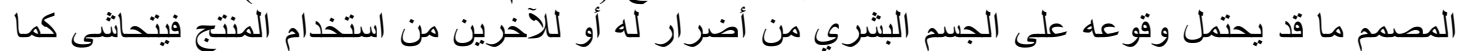

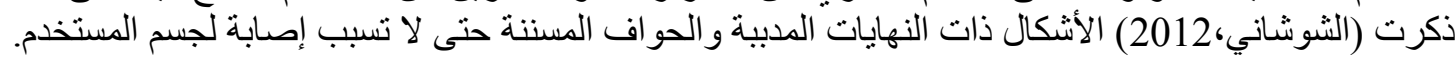

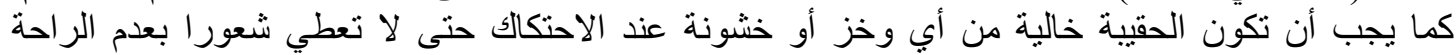

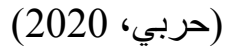

كما يجب مر اعاة وملائمة تصميم المنتج للجو انب السيكولوجية للمستخدم ووظائف أعضاؤه و أبعادها حيث تهتم

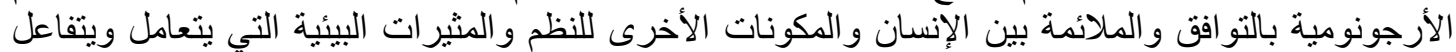

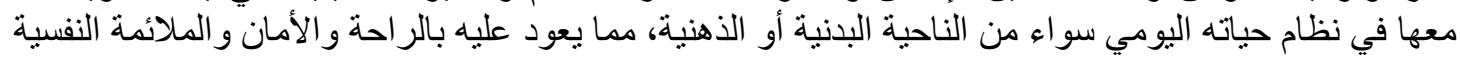

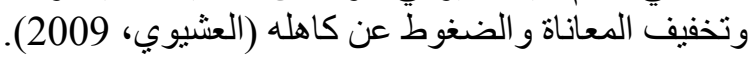

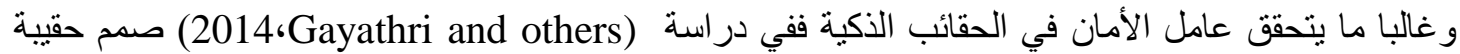

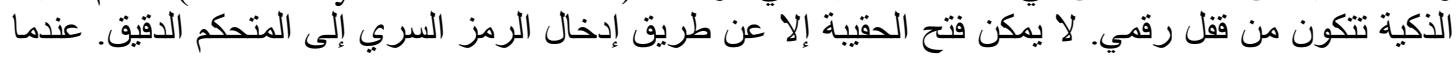

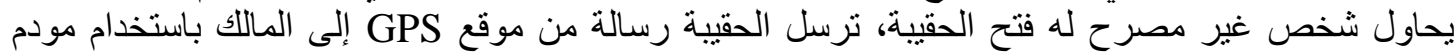

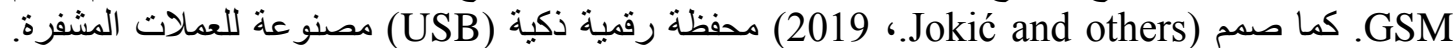
توفر اهتمام خاص للأمان بالإضافة إلى خيار قفل المحفظة باستخدام الرمز السري والنسخ الاحتياطي

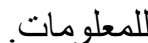

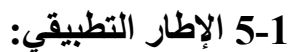

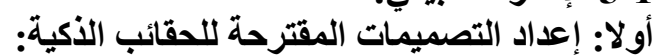

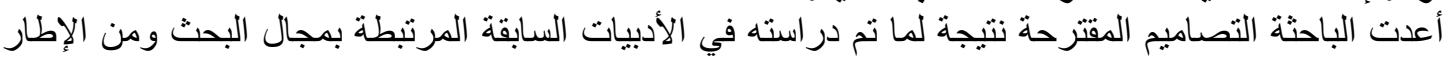

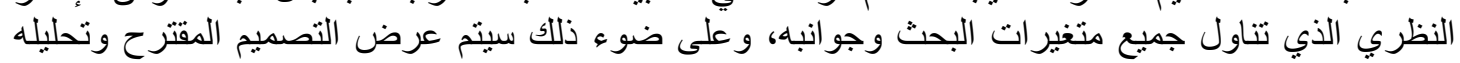

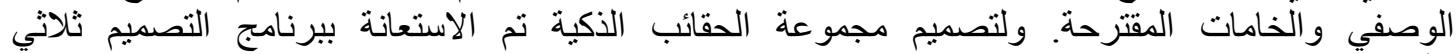
الأبعاد 6.1 CLO 


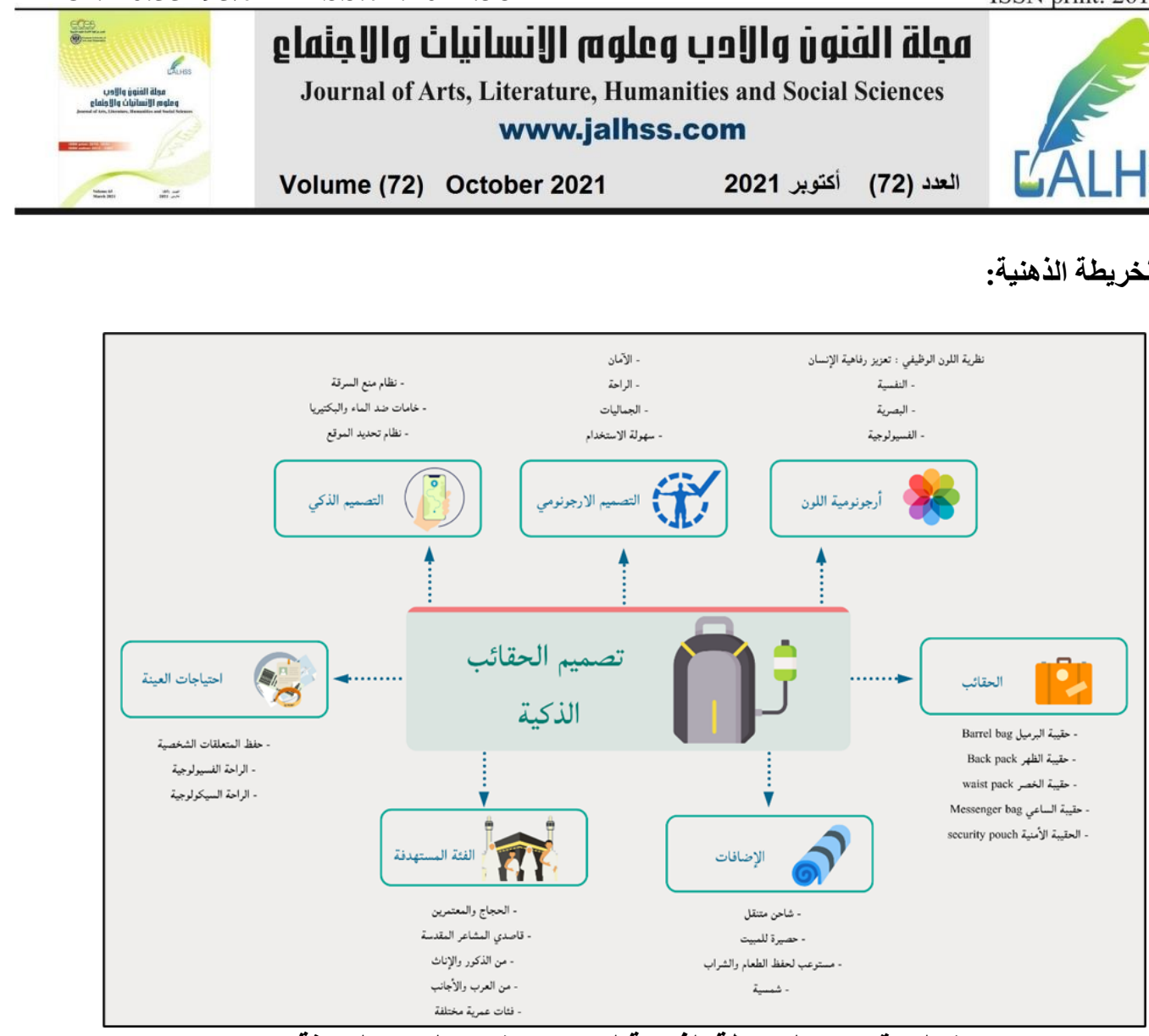

شكل رقم (4) الخريطة الذهنية لتصميم حقائب الحج (الباحثة)

وقد قامت الباحثة بإعداد 6 تصميمات مقترحة لحقائب الحج والعمرة الذكية، وفيما يلي عرض تفصيلي

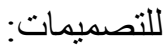
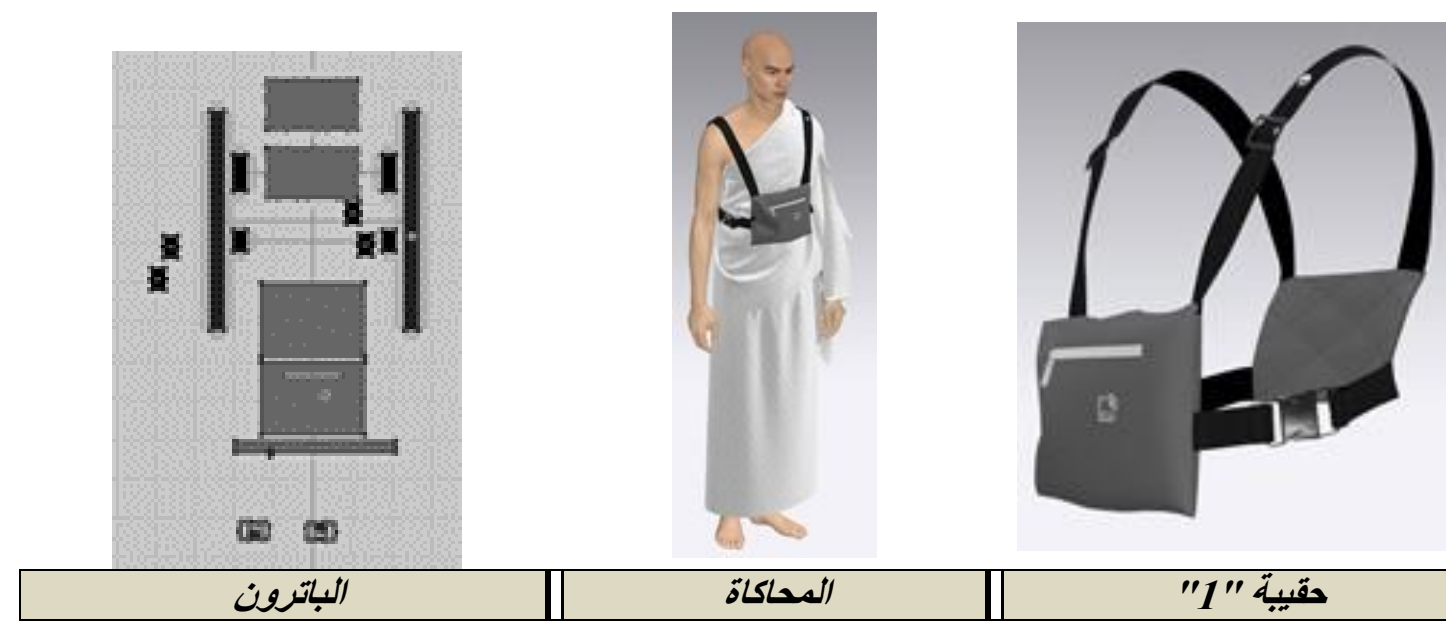

الباترون

المحاكاة

حقبية "1"1" 


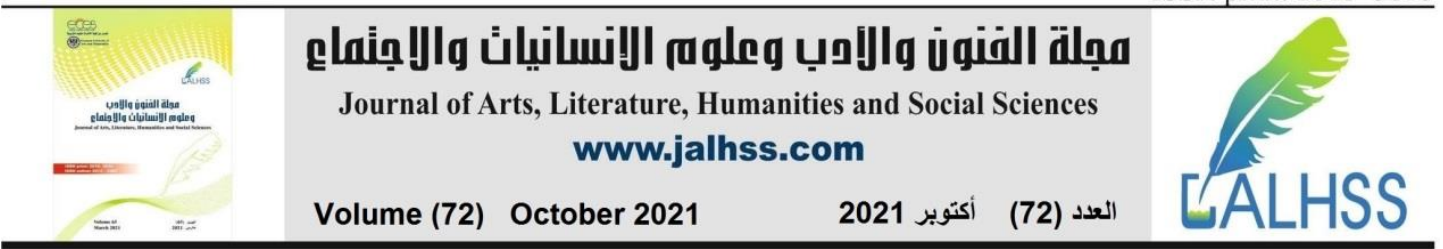
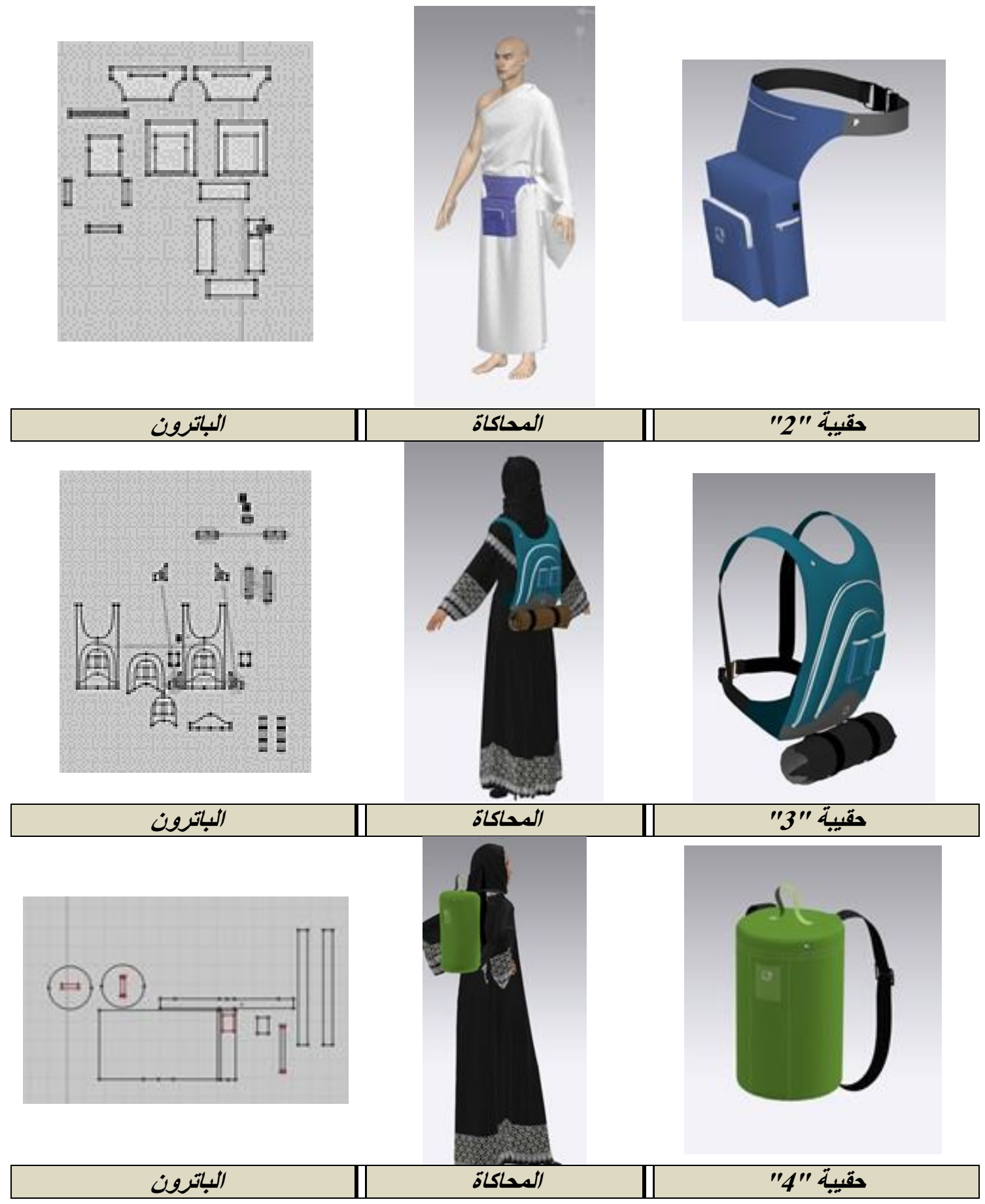


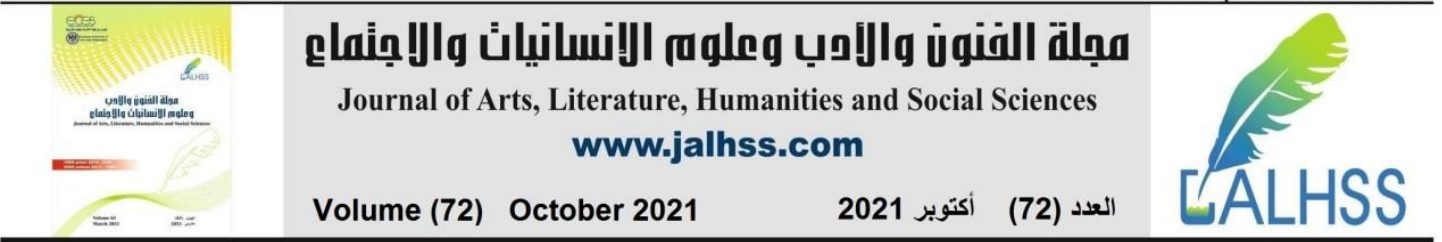
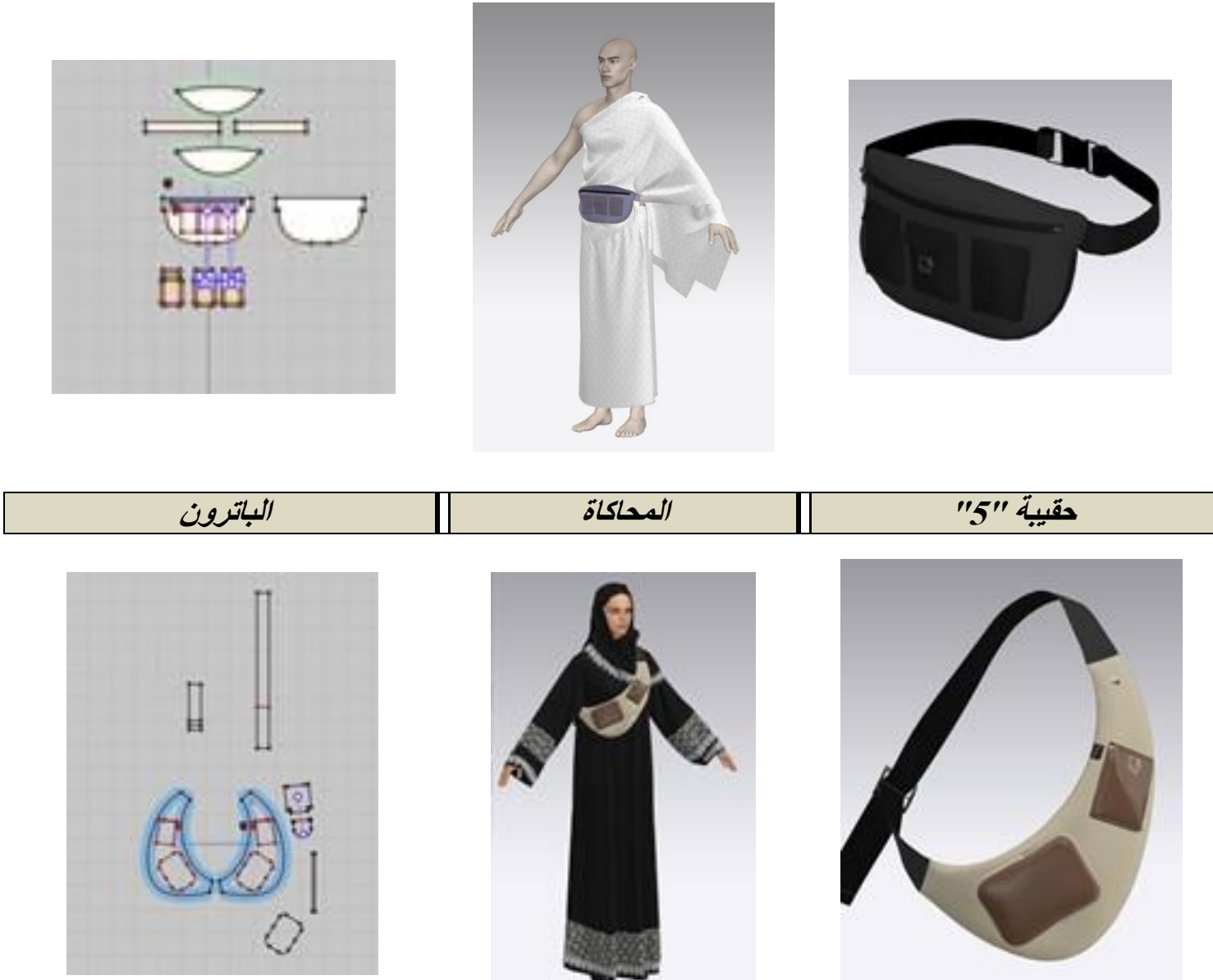

شكل رقم (5) التصاميم المقترحة للحقائب الذكية
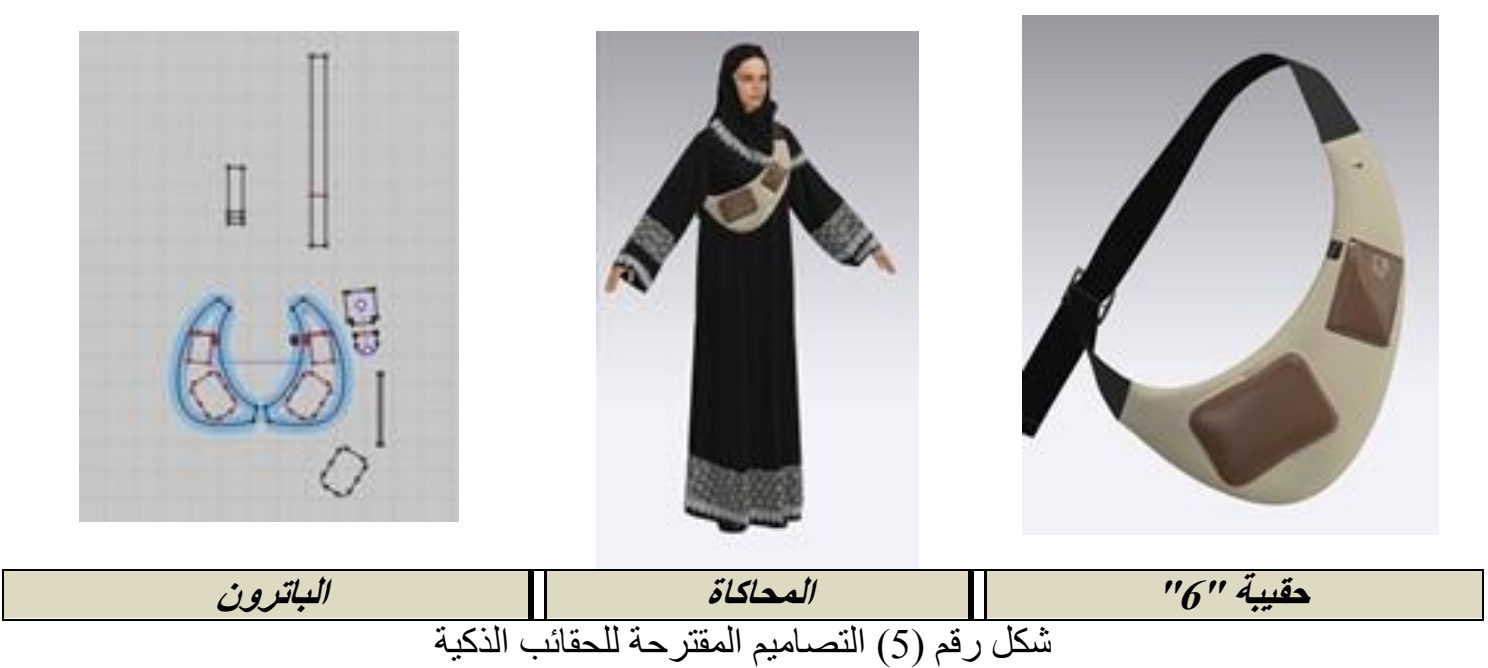

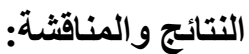

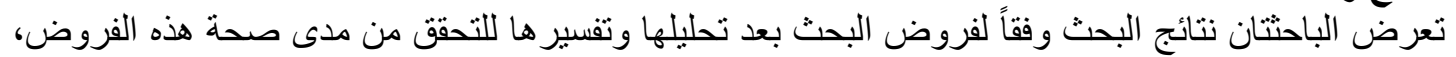

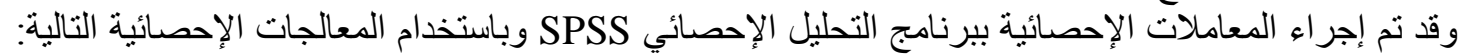

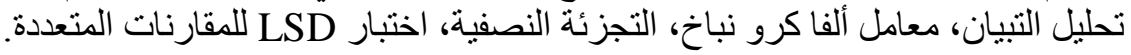

"توجد فروق ذات دلالة إحصائية بين التصميمات الست المقترحة للحقائب الذكية في تحقيق القيم الجمالية وفقا

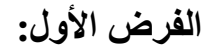

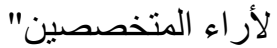
وللتحقق من هذا الفرض تلم حساب تحليل التباين لمنتوسط درجات التصميمات الست المقترحة للحقائب الذكبة في

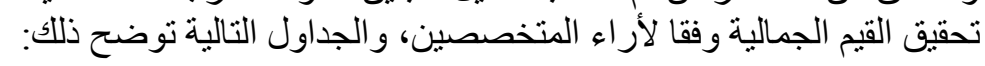




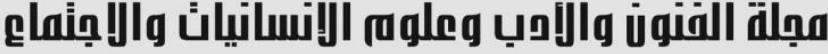

Journal of Arts, Literature, Humanities and Social Sciences www.jalhss.com

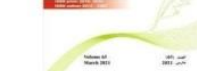

\section{Volume (72) October 2021}

2021 كتوبر

العدد (72) (2) (2)

\section{LALHSS}

\begin{tabular}{|c|c|c|c|c|c|}
\hline \multicolumn{6}{|c|}{ لأراء المتخصصين } \\
\hline الدلالة الد & قيمة (ف) & درجية & متوسط المربعات & مجموع المربعات & تحقيق القيم الجمالية \\
\hline \multirow[t]{3}{*}{ 0.01 دال } & \multirow[t]{2}{*}{47.337} & 5 & 626.588 & 3132.939 & بين المجمو عات \\
\hline & & 60 & 13.237 & 794.201 & داخل الدجمو عات \\
\hline & & 65 & & 3927.140 & المجموع \\
\hline
\end{tabular}

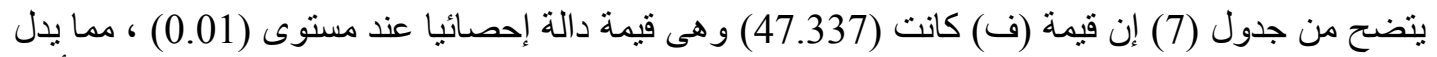

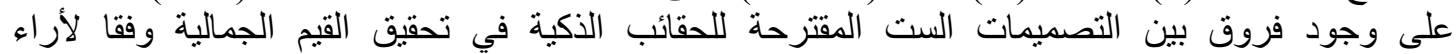

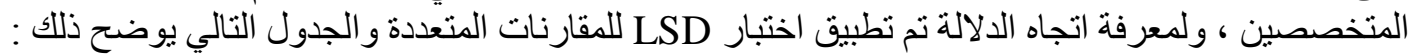

جدول (8) اختبار LSD للمقارنات المتعددة

\begin{tabular}{|c|c|c|c|c|c|c|}
\hline 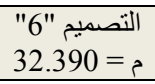 & التصميم "5" 24.652 " & 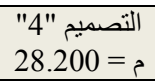 & التصميم "314"114 & م= التصميم "20.702" & م= التصميم "15.698" & تحقيق القيم الجمالية \\
\hline & & & & & - & التصميم "1" \\
\hline & & & & - & $* * 14.995$ & التصميم "2" \\
\hline & & & - & $* * 3.588$ & $* * 18.583$ & التصميم "3" \\
\hline & & - & $* * 11.085$ & $* * 7.497$ & $* * 7.498$ & التصميم "4" \\
\hline & - & $* * 3.547$ & $* * 7.538$ & $* * 3.950$ & $* * 11.045$ & التصميم "5" \\
\hline - & $* * 7.738$ & $* * 4.190$ & $* * 15.276$ & $* * 11.688$ & **3.307 & التصميم "6" \\
\hline
\end{tabular}

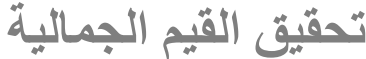

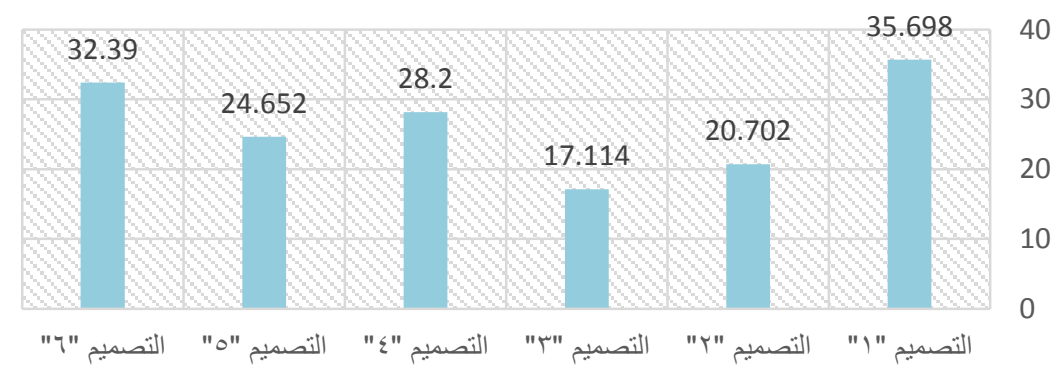

شكل (6) يوضح متوسط درجات التصميمات المقترحة للحقائب الذكية في تحقيق القيم الجمالية وفقا لأراء المتخصصين

من الجدول (8) و الثنكل (6) يتضح وجود فروق دالة إحصائبا بين التصميمات الست المقترحة للحقائب الذكية

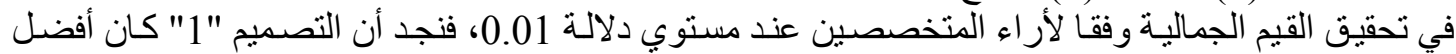

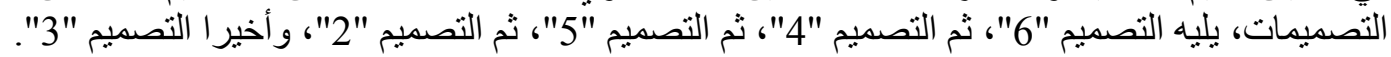
"توجد فروق ذات دلالة إحصائية بين التصميمات الست المقترحة للحقائب الذكية في تحقيق القيم الوظيفية

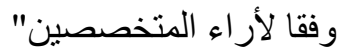
وللتحقق من هذا الفرض تم حساب تحليل التباين لمتوسط درجات التصميمات الست المقترحة للحقائب الذكية

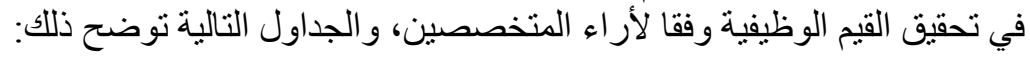




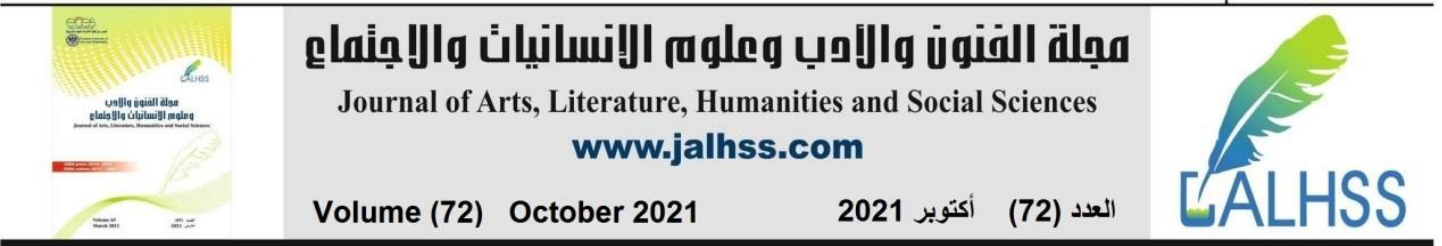

جدول (9) تحليل التباين لمتوسط درجات التصميمات المقترحة للحقائب الذكية في تحقيق القيم الوظيفية وفقا لأراء المتخصصين

\begin{tabular}{|c|c|c|c|c|c|}
\hline الدلالة & قيمة (ف) & الحرية & متوسط المربعات & مجموع المربعات & تحقيق القيم الوظيفية \\
\hline \multirow{3}{*}{0.01 دال } & \multirow[t]{3}{*}{60.534} & 5 & 386.930 & 1934.651 & بين المجموعات \\
\hline & & 60 & 6.392 & 383.516 & داخل المجموعات \\
\hline & & 65 & & 2318.167 & المجموع \\
\hline
\end{tabular}

يتضح من جدول (9) إن قيمة (ف) كانت (60.534) و هي قيمة دالة إحصائيا عند مستوى (0.01)، مما يدل على وجود

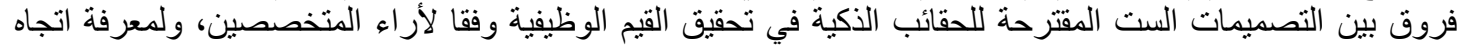

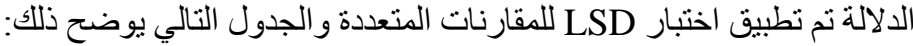

جلول (10) ألمتبار LSD للمقارنات المتعددة

\begin{tabular}{|c|c|c|c|c|c|c|}
\hline م = التصيميم "6.522" 38.5 & م= التصميم "5.089" & م= =تصميم "4.219" & م= التصميم "31.354" & التصميم "29.190" 29.1 & م = التصميم "15.541" & تحقيق القيم الوظيفية \\
\hline & & & & & - & التصميم "1" \\
\hline & & & & - & $* * 6.350$ & التصميم "2" \\
\hline & & & - & $* 2.163$ & $* * 4.187$ & التصميم "3" \\
\hline & & - & $* * 6.135$ & **3.971 & $* * 10.322$ & "التصميم "4" \\
\hline & - & $* * 6.130$ & $* * 12.265$ & $* * 10.101$ & $* * 16.452$ & التصميح "5" \\
\hline - & $* * 19.433$ & $* * 13.303$ & **7.168 & $* * 9.331$ & $* 2.980$ & التصميح "6" \\
\hline
\end{tabular}

\section{تحقيق القيم الوظيفية}

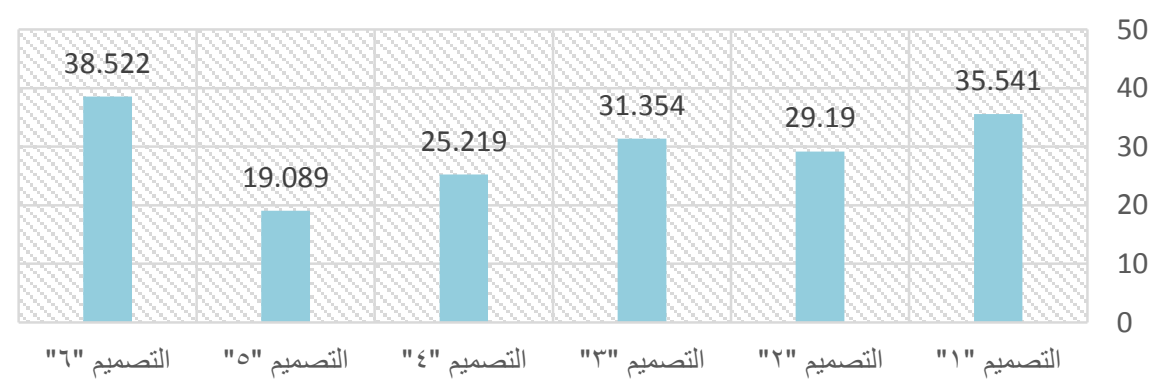

شكل (7) يوضح متوسط درجات التصميمات المقترحة للحقائب الذكية في تحقيق القيم الوظيفية وفقا لأراء المتخصصين

من الجدول (10) و الثكل (7) يتضح وجود فروق دالة إحصائيا بين التصميمات الست المقترحة للحقائب الذكية

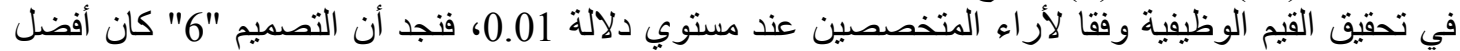

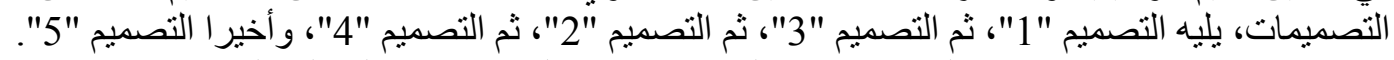

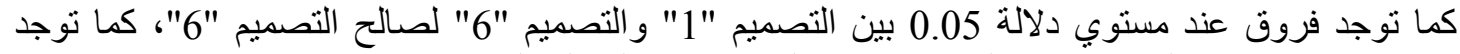

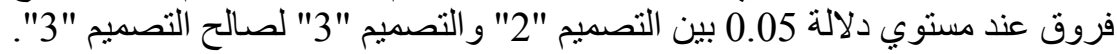

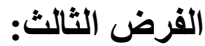
"توجد فروق ذات دلالة إحصائية بين التصميمات الست المقترحة للحقائب الذكية في الأمان وفقا لأراء 


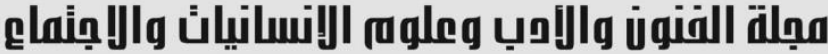

Journal of Arts, Literature, Humanities and Social Sciences www.jalhss.com

\section{Volume (72) October 2021}

أكتوبر 2021

العدد (72) (17)

\section{LALHSS}

وللتحقق من هذا الفرض تم حساب تحليل التباين لمتوسط درجات التصميمات الست المقترحة للحقائب الذكية في الأمان وفقا لأر اء المتخصصين، و الجداول التالية توضح ذلكئ لئل

جدول (11) تحليل التباين لمتوسط درجات التصميمات المقترحة للحقائ الأكية في الأمان وفقا لأراء المتخصصين

\begin{tabular}{|c|c|c|c|c|c|}
\hline 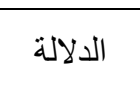 & قيمة (ف) & الحربة & متوسط المربعات & مجموع المربعات & الأمان \\
\hline \multirow{3}{*}{0.010} & \multirow{2}{*}{33.538} & 5 & 698.160 & 3490.798 & بين المجمو عات \\
\hline & & 60 & 20.817 & 1249.026 & داخل المجموعات \\
\hline & & 65 & & 4739.824 & المجموع \\
\hline
\end{tabular}

يتضح من جدول (11) إن قيمة (ف) كانت (33.538) و هي قيمة دالة إحصائيا عند مستوى (0.01)، مما يدل

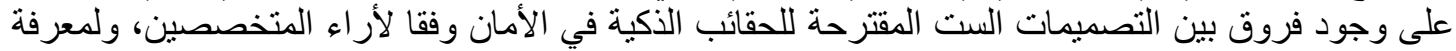
اتجاه الدلالة تم تطبيق اختبار LSD للمقارنات المتعددة و الجدول التالي يوضي الأنح ذلك:

جدول (12) اختبار LSD للمقارنات المتعددة

\begin{tabular}{|c|c|c|c|c|c|c|}
\hline م= التصميم "6.815" & م= =لتصبيم "5.032" & التصميم "4 "4.392" & 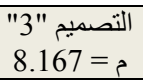 & 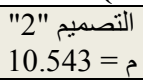 & التصميم "1"1" 20.658 م & الأمان \\
\hline & & & & & - & التصميم "1" \\
\hline & & & & - & $* * 10.114$ & التصميح "2" \\
\hline & & & - & *2.376 & $* * 12.490$ & التصميم "3" \\
\hline & & - & $* * 4.225$ & 1.849 & $* * 8.265$ & التصميم "4" \\
\hline & - & **5.640 & $* * 9.865$ & **7.489 & $* 2.625$ & التصميم "5" \\
\hline - & $* 2.217$ & $* * 3.422$ & $* * 7.648$ & $* * 5.271$ & $* * 4.842$ & التصميم "6" \\
\hline
\end{tabular}

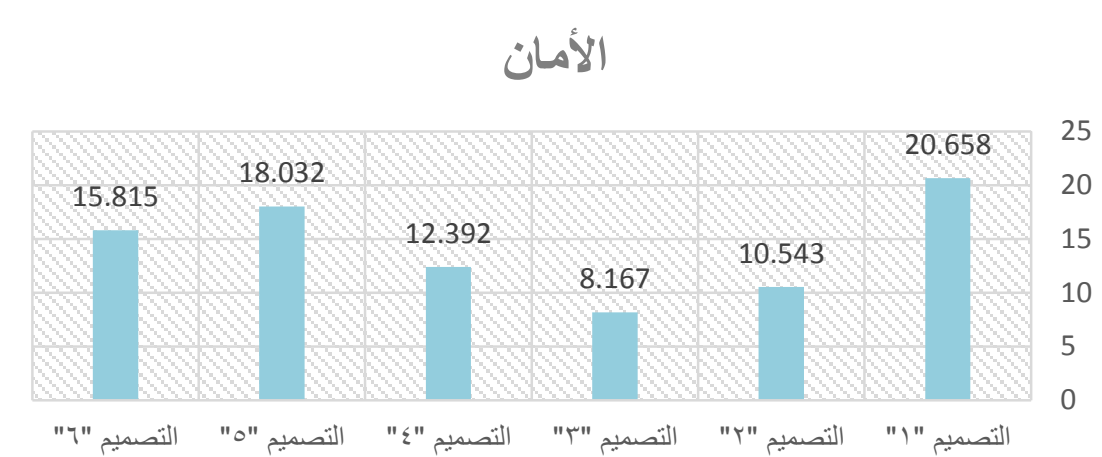

شكل (8) يوضح متوسط درجات التصميمات المقترحة للحقائب الذكية في الأمان وفقا لأراء المتخصصين

من الجدول (12) و الثكل (8) يتضح جود فروق دالة إحصـائيا بين التصميمات الست المقترحة للحقائب الذكية

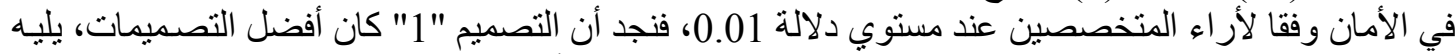

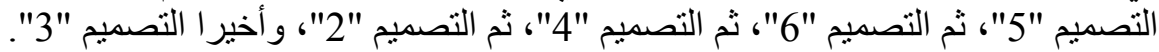

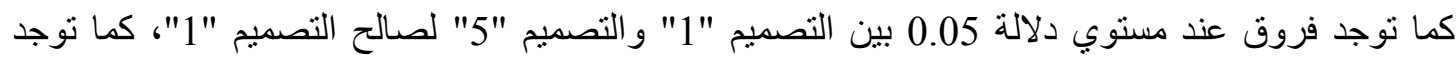

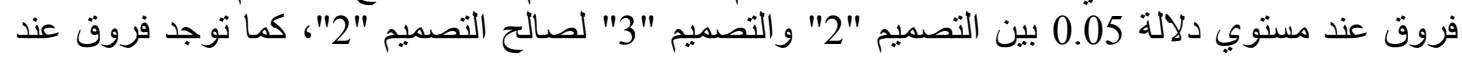

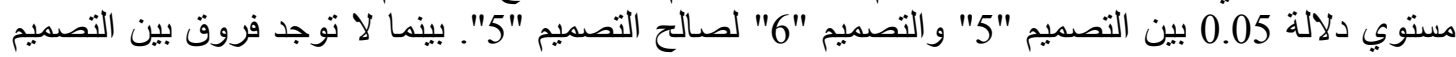

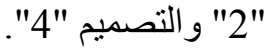


"توجد فروق ذات دلالة إحصائية بين التصميمات الست المقترحة للحقائب الذكية في سـهولة الاستخدام وفقا

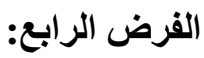

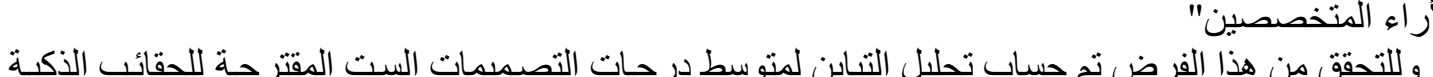

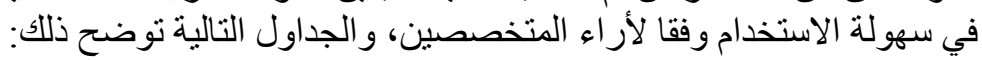

جدول (13) تحليل التباين لمتوسط درجات التصميمات المقترحة للحقائ الذكية في سهولة الاستخدام وفقا لأراء

\begin{tabular}{|c|c|c|c|c|c|}
\hline \multicolumn{6}{|c|}{ المتخصصين } \\
\hline الدالة & قيمة (ف) & درجرية & متوسط المربعات & مجموع المربعات & سهولة الاستخدام \\
\hline \multirow[t]{3}{*}{ (0.01 دال } & \multirow[t]{3}{*}{51.011} & 5 & 298.952 & 1494.759 & بين المجمو عات \\
\hline & & 60 & 5.861 & 351.633 & داخل المجمو عات \\
\hline & & 65 & & 1846.392 & المجموع \\
\hline
\end{tabular}

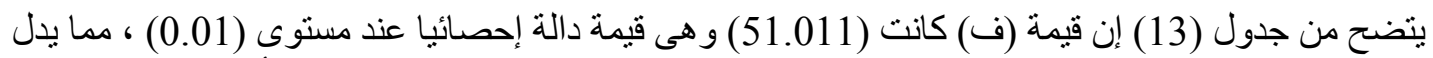

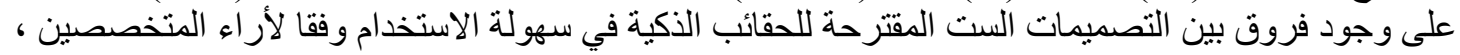

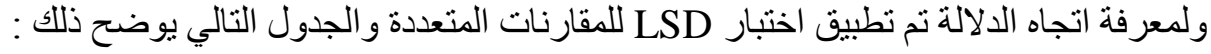

جدول (14) اختبار LSD للمقارنات المتعددة

\begin{tabular}{|c|c|c|c|c|c|c|}
\hline التصميج "6" & التصميم "5" & التصميع "4" & التصميح "3" & التصميم "2" & التصميج "1" & كهولة الاستخدام \\
\hline م 18.882 & م & $8.843=p$ & $12.407=$ ? & $23.763=p$ & $21.790=$ p & \\
\hline & & & & & 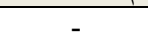 & التصميح "1" \\
\hline & & & & - & 1.972 & التصميم "2" \\
\hline & & & - & ${ }^{* *} 11.356$ & $* * 9.383$ & التصميم "3" \\
\hline & & - & $* * 3.563$ & $* * 14.920$ & $* * 12.947$ & التصميم "4" \\
\hline & - & $* * 4.828$ & 1.264 & $* * 10.091$ & $* * 8.119$ & التصميم "5" \\
\hline - & **5.210 & $* * 10.039$ & $* * 6.475$ & $* * 4.880$ & $* 2.908$ & التصميم "6" \\
\hline
\end{tabular}

\section{سهولة الاستخدام}

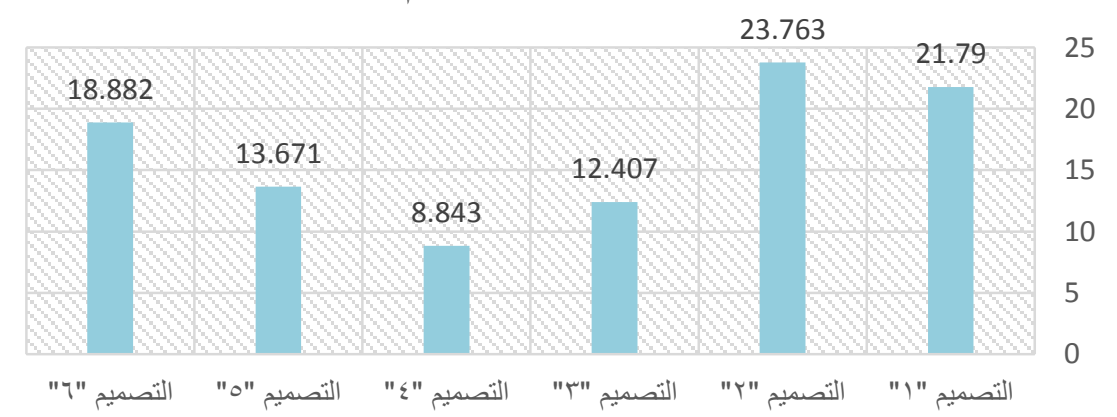

شكل (9) يوضح متوسط درجات التصميمات المقترحة للحقائب الأكية في سهولة الاستخدام وفقا لأراء المتخصصين 


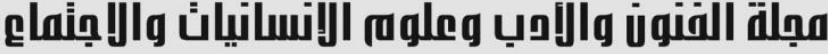

Journal of Arts, Literature, Humanities and Social Sciences www.jalhss.com

\section{Volume (72) October 2021}

2021 أكتوبر

العدد (72) (17)

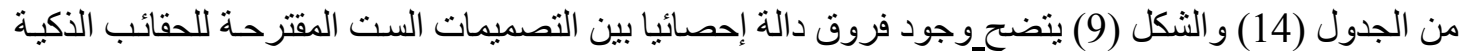

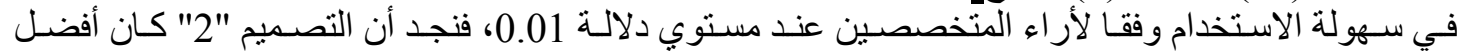

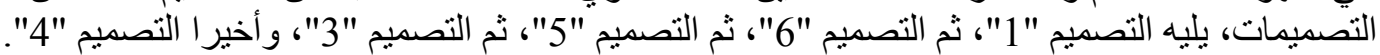

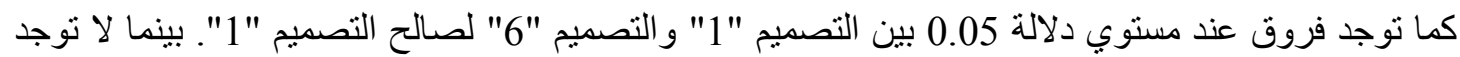

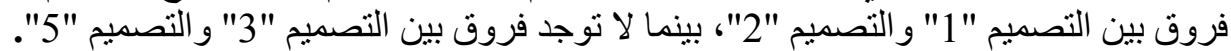

"توجد فروق ذات دلالة إحصائية بين التصميمات الست المقترحة للحقائب الذكية وفقا لأر اء المتخصصين" وللتحقق من هذا الفرض تم حساب تحليل التباين لمتوسط درجات التصميمات الست المقترحة للحقائب الذكية وفقا لأر اء المتخصصين، والجداول النّالية توضح ذلك:

جدول (15) تحليل التباين لمتوسط درجات التصميمات المقترحة للحقائب الذكية وفقا لأراء المتخصصين

\begin{tabular}{|c|c|c|c|c|c|}
\hline الدلالة & قيمة (ف) & الحرية & متوسط المربعات & مجموع المربعات & "المجموع الكلي" \\
\hline \multirow[t]{3}{*}{0.01 دال } & \multirow[t]{2}{*}{45.520} & 5 & 4728.926 & 23644.629 & بين المجمو عات \\
\hline & & 60 & 103.887 & 6233.209 & داخل المجمو عات \\
\hline & & 65 & & 29877.838 & المجموع \\
\hline
\end{tabular}

يتضح من جدول (15) إن قيمة (ف) كانت (45.520) وهى قيمة دالة إحصائيا عند مستوى (0.01) ، مما يدل

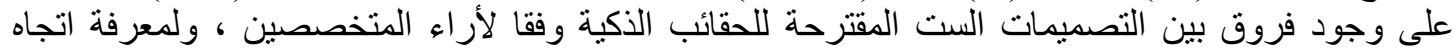

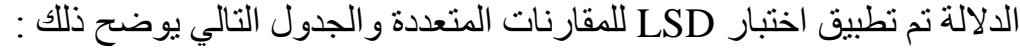

جدول (16) اختبار LSD للمقارنات المتعددة

\begin{tabular}{|c|c|c|c|c|c|c|}
\hline $\begin{array}{c}6 \\
\end{array}$ & م= التصميم "5 =746.446 & التصسيم "4.655" & التصميم "39.043" & $\begin{array}{l}\text { التصميم "200"24.200 } \\
84 .\end{array}$ & م= = التصميم "13.689"113. & المجموع الكلي "المتخصصين" \\
\hline & & & & & - & التصميم "1" \\
\hline & & & & - & $* * 29.488$ & التصميم "2" \\
\hline & & & - & $* * 15.157$ & $* * 44.645$ & التصميم "3" \\
\hline & & - & $* * 5.611$ & $* * 9.545$ & $* * 39.033$ & التصميم "4" \\
\hline & - & 0.790 & $* * 6.402$ & $* * 8.754$ & $* * 38.242$ & التصميم "5" \\
\hline- & $* * 30.165$ & $* * 30.956$ & $* * 36.568$ & $* * 21.410$ & **8.077 & التصميم "6" \\
\hline
\end{tabular}




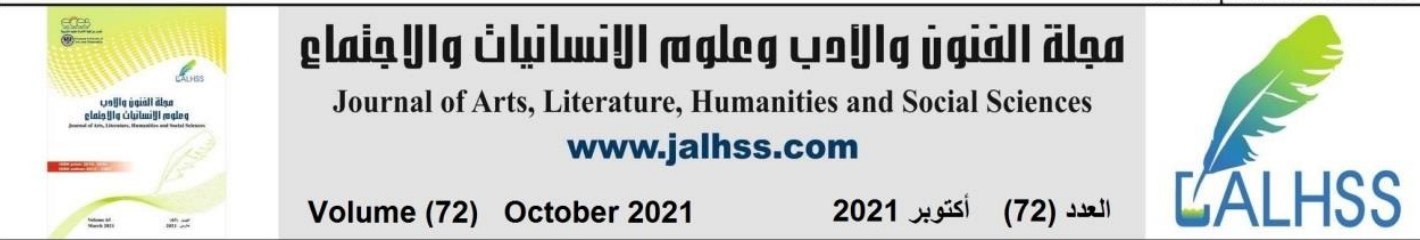

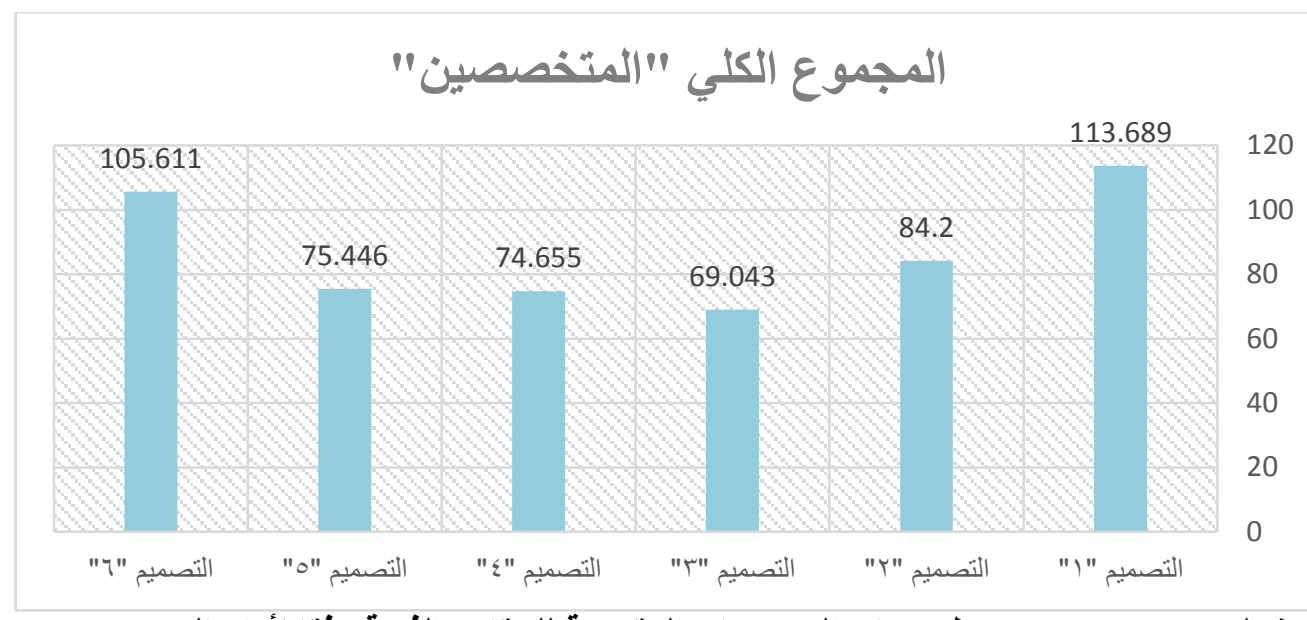

شكل (10) يوضح متوسط درجات التصميمات المقترحة للحقائب الأكية وفقا لأراء المتخصصين

من الجدول (16) و الثكل (10) يتضح وجود فروق دالة إحصائيا بين التصميمات الست المقترحة للحقائب الذكية

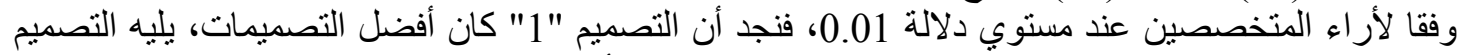

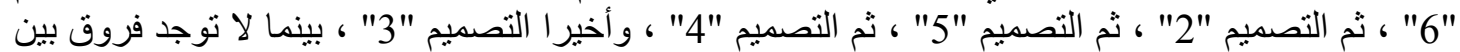

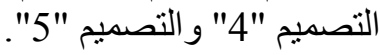

وقد توصلت الدراسة إلى جملة استتناجات علمية وهي:

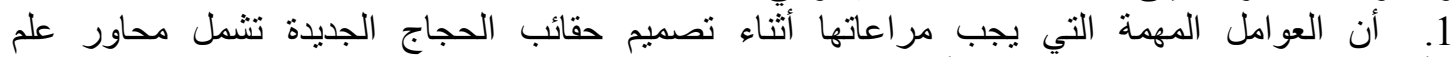

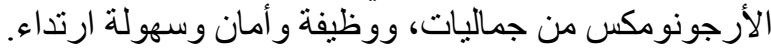

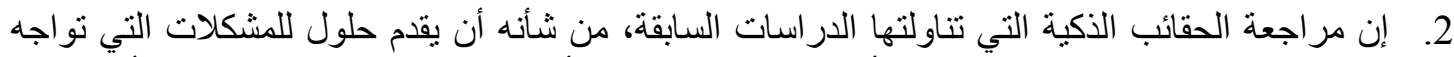

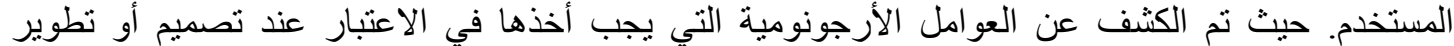

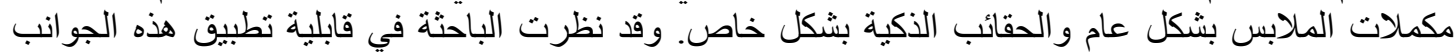

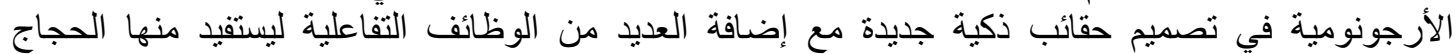

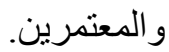

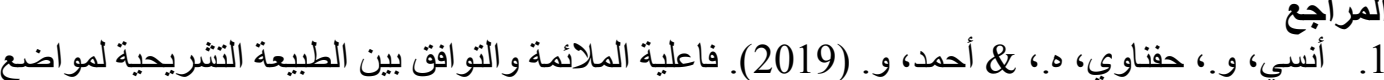

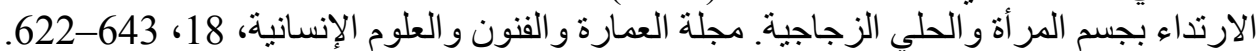

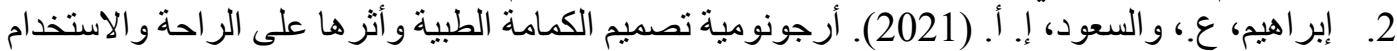

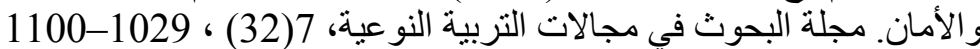

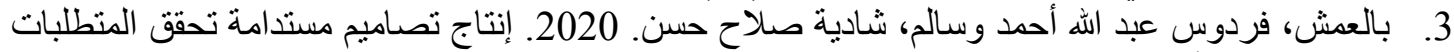

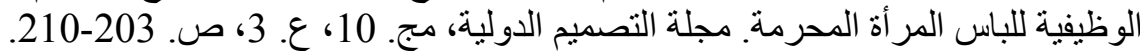

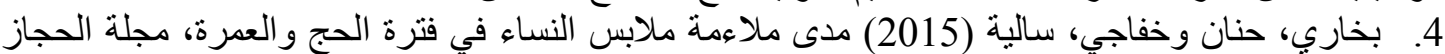
العالمية المحكمة للار اسات الإسلامية والعربية العبية، جدة، المملكة العربية السعودية.

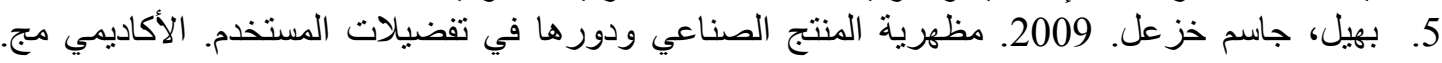

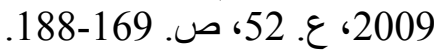

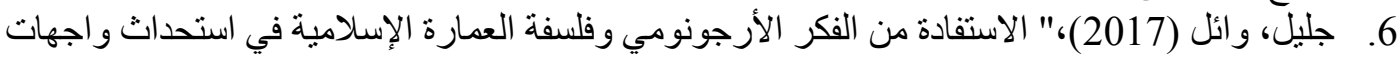

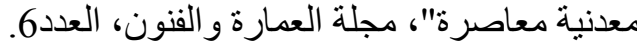

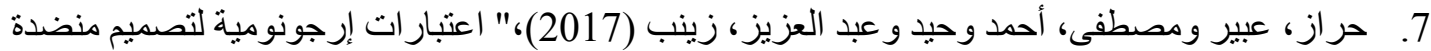
التفصيل"، مجلة التصميم الدولية، المجلد 7، العدد3. 


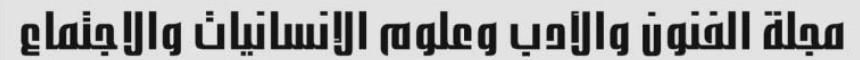

Journal of Arts, Literature, Humanities and Social Sciences www.jalhss.com

\section{Volume (72) October 2021}

2021 كتوبر

العدد (72)

8. حربي، س. (2020). الاعتبار ات الأرجونومية لحقيبة اليد الخاصة بالمر أة العاملة و أثر ها على الأداء

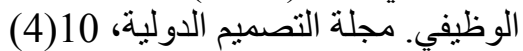
9. الحسني، علا (2020). تصميم زي للمر أة لأداء مناسك الحج والعمرة. المجلة الدولية للعلوم الإنسانية

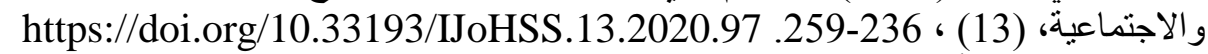

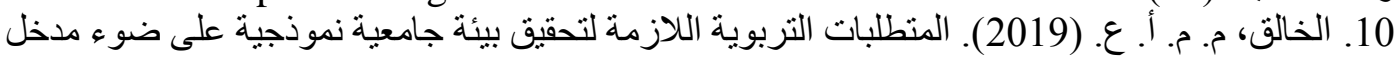

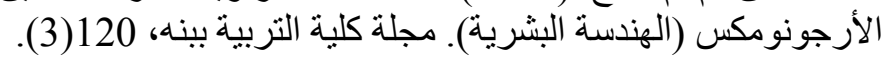

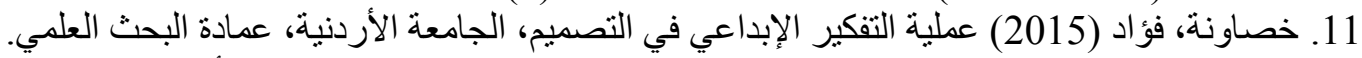

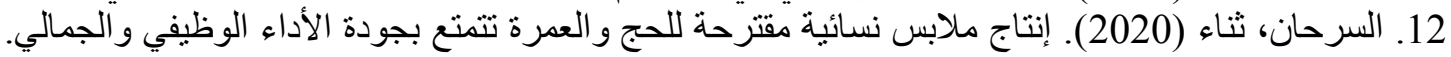

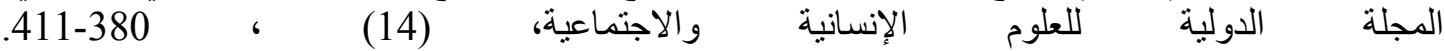
https://doi.org/10.33193/IJoHSS.14.2020.124

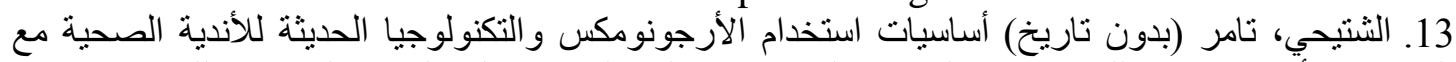

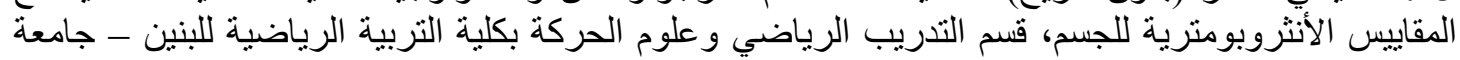

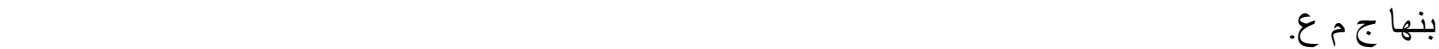
14. الثشوشاني، ه. ر. (2012). تحقيق الارجونومية الوظيفية للحلى النسجية في ضوء المفهوم المعاصر للتربية

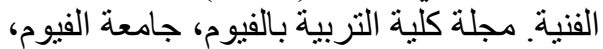
15. طعيمة، نجلاء (2018) دراسة تحليلية لألئية لأوشحة زوار بيت الله الحرام (التصميم والتطبيق)، مجلة العمارة و الفنون، العدد الحادي عشر. 16. عيسى، إ. ب. (2017). تصميم العمل وفق الجئ البعد الأرجونومي وعلاقته بجودة حياة العمل لدى مهندسي

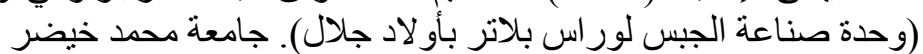

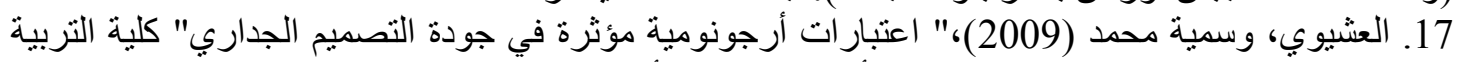

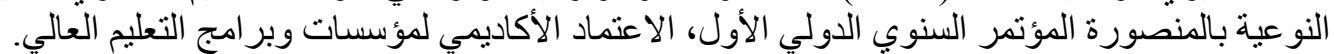

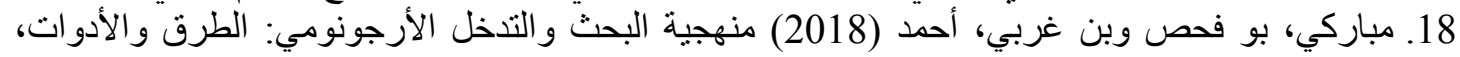

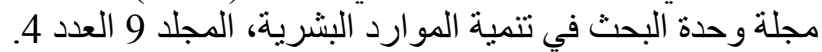
19. مصطفى، سامي و وعلي، أحمد و السيد، ناهية النية (2017) التقنية الجمالية وتصميم شكل المنتج، مجلة بحوث

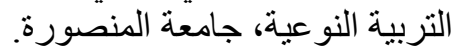

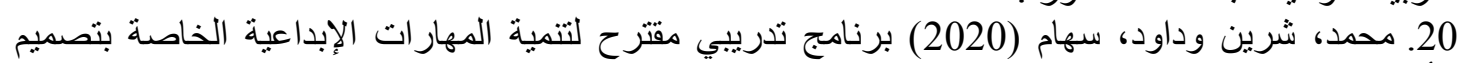

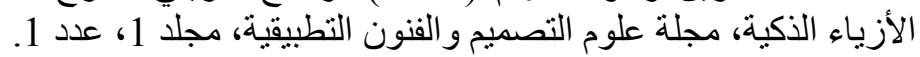

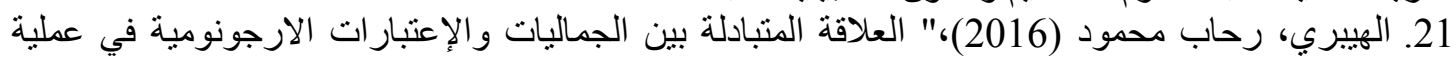

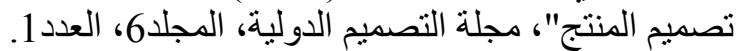
22. Abhang, A. L., Mahale, C. L., Desai, V. R., \& Biswas, P. (2018). Smart Bag. International Journal of Scientific Research in Scienceand Technology .(7) ‘

23. BERLIN, C. (2011). Ergonomics infrastructure-an organizational roadmap to improved production ergonomics. CHALMERS UNIVERSITY OF TECHNOLOGY. 24. E.Nada, Osama. (2019). Ergonomics of Wearable Technologies. Journal of Architecture and Arts and humanistic sciences, 4(14), 36-50doi: 10.21608/mjaf.2019.25767

25. Emara, M. G., \& Abou-Taleb, E. M. Improving the Performance of Terry Fabrics to be used as Pilgrimage Clothes. International design journal, 10(3), 397.

26. Fawzy, Germin, Mohammed, Hend, Mahdy, Omneya. (2020). the Development of Metal Handbags for Decoration Based OnModern Artistic Trends. Journal of Architecture and Arts and humanistic sciences, 5(19), 207-2215. doi: 10.21608/mjaf.2019.13987.1211.

27. Leeuwen, Anthony (2013)," Reusable Bags and Ergonomic Issues". 


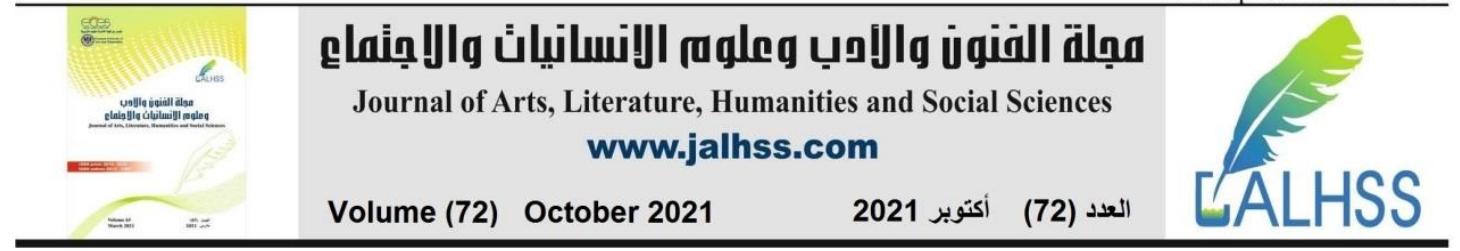

28. .Gindi, S., Ansari, I., Khan, K., \& Bilal, F. (2016). SmartTag Using Solar and RFID Technology. imperial Journal of Interdisciplinary Research,

29. Gayathri, P and Abhirami, K and Sivaranjani, T (2014) Pervasive Interaction Smart Bag Using RFID Technology. International Journal of Engineering and Innovative Technology. Volume 3, Issue 9. ISSN: 2277-3754.

30. Harbauer, C. M., Fleischer, M., Nguyen, T., Bos, F., \& Bengler, K. (2020). Too Close to Comfort? A New Approach of Designing a Soft Cable-Driven Exoskeleton for Lifting Tasks under Ergonomic Aspects. 105-109. https://doi.org/10.1109/irce50905.2020.9199238

31. Jokić, Stevo \& Cvetković, Aleksandar Sandro \& Adamović, Saša \& Ristić, Nenad \& Spalević, Petar. (2019). Comparative analysis of cryptocurrency wallets vs traditional wallets. Ekonomika. 65. 10.5937/ekonomika1903065J.

32. Sebin and others (2017) SMART BAG (It can follow you)

33. Shaker, Amani Mohamed and Al-Maddah, Dalia El-Sayed (2017). Making use of the cosmetic and aesthetic values of the non-woven fabric method in the production of innovative handbags, Fourth and International Scientific Conference II: Qualitative Education: The Challenges of Modernization and the Challenges of Culture, Ain Shams University, Egypt.

34. Teyeme, Yetanawork \& Malengier, B. \& Tesfaye, Tamrat \& Ciesielska, Izabela \& Musa, Atiyyah \& Van Langenhove, Lieva. (2020). A Review of Contemporary Techniques for Measuring Ergonomic Wear Comfort of Protective and Sport Clothing. Autex Research Journal. 21. 10.2478/aut-2019-0076.

1. https://theaquavault.co/products/flexsafe 2021/9/19 تاريخ الدخولتح

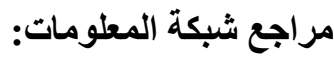

2.

3. تاريخ الدخول 2021/9/18

4. Eww.universalis.fr 2021/9/11 تاريخ الدخول 